\title{
The Asymmetric Momentum Effect in the Chinese Class A Share Market Amid Market Swings
}

\author{
Yuan $\mathrm{Wu}^{1}$
}

Published online: 7 March 2016

(C) The Author(s) 2016. This article is published with open access at Springerlink.com

\begin{abstract}
This paper investigates the asymmetric momentum effect over time periods following UP and DOWN market states in the Shanghai and Shenzhen Stock Exchanges of the Chinese Class A share market. We show that the post-UP-market momentum effect eclipses the post-DOWN-market momentum effect in unison in both market segments. Notably, the asymmetric pattern of the market-state-dependent momentum effect in the Shenzhen Stock Exchange is outpaced by that found in the Shanghai Stock Exchange. Furthermore, through decomposing momentum returns, we reveal that low liquidity, higher market return volatility, and weak under-reaction of share prices towards firm-specific news jointly contribute to the subdued asymmetry of market-state-dependent momentum returns in the Shenzhen Stock Exchange.
\end{abstract}

Keywords Asymmetry - Momentum effect - Chinese Class A share market . Decomposition of momentum returns · Market states

JEL Classification $\quad \mathrm{G} 02 \cdot \mathrm{G} 12 \cdot \mathrm{G} 14 \cdot \mathrm{G} 15$

\section{Introduction}

Since the momentum effect was first documented by Jegadeesh and Titman (1993) in their seminal work Returns to Buying Winners and Selling Losers: Implications for Stock Market Efficiency, investigations around its existence have been conducted from various perspectives. Recently, increasingly more researchers recognise the market-

Yuan Wu

yuan.wu@uwe.ac.uk

1 Bristol Business School, University of the West of England, Frenchay Campus, Coldharbour Lane, Bristol BS16 1QY, UK 
state-dependent nature of the momentum effect and are documenting the dynamics of the momentum effect under different market states in different financial markets. Specifically, Cooper et al. (2004), Huang (2006) and Du et al. (2009) ${ }^{1}$ unanimously showed that the momentum effect found over post-UP-market states eclipses that found over post-DOWN-market states in an international setting. In one of the most recent studies on the momentum effect in the Chinese stock market, Wu and Choudhry (2015) investigate the differences between the anomalous phenomenon in the Chinese Class A and B share markets.

In this study, we investigate the asymmetric patterns of market-state-dependent momentum returns found among Chinese Class A shares listed on the Shanghai Stock Exchange (SHSE hereafter) and the Shenzhen Stock Exchange (SZSE hereafter). Furthermore, we examine how market risk, liquidity risk, market volatility, and an under-reaction of share prices towards firm-specific information factors contribute to the asymmetric patterns of the market-state-dependent momentum returns in the SHSE and the SZSE. ${ }^{2}$ We employ a method analogous to the method used by Cooper et al. (2004), and analyse a dataset consisting of monthly stock returns over a time horizon from January 1996 to December 2010. The market states are defined by prior 12-month average market returns ${ }^{3}$ of the SHSE and SZSE.

A highly contestable issue such as this, i.e. the market-dependent nature of the momentum effect in the context of the Chinese capital market, is worth investigating for the following reasons: first of all, the Chinese economy has established itself as the engine of world economic growth in recent years, with its stock market accounting for an increasingly large part in the economy (40.37\% of GDP in 2008). ${ }^{4}$ Despite being a nascent financial market, it is widely agreed that the Chinese stock market is weakly interrelated with other developed financial markets such as the US and the UK, offering sufficient diversification opportunities for international investors (Lin and Swanson 2008; Phylaktis and Ravazzolo 2005). Secondly, the Chinese stock market has some unique characteristics such as the segmented markets (Class A and Class B shares; SHSE and SZSE; and the split between tradable and non-tradable shares). Finally, despite the fact that the Chinese stock market is rich in behavioural phenomena, there are few prior studies carrying out rigorous analysis particularly from the perspective of behavioural finance.

This paper extends the understanding of the dynamics of the market-state-dependent momentum effect by offering extensive evidence on the distinct asymmetric patterns of the market-state-dependent momentum effect in the two segments of the Chinese Class A share market-the SHSE and the SZSE. More specifically, the empirical

\footnotetext{
1 Du et al. (2009) showed that the overall subdued momentum effect in the Taiwanese stock market can be attributed to overwhelmingly negative momentum returns yielded over the post-DOWN-market state.

2 The Chinese Class B share market is precluded from the analysis on the dynamics of market-statedependent momentum returns states due to the concerns over liquidity and microstructure particularly at the early stage in the development of the market segment (Naughton et al. 2008; Wang and Chin 2004).

3 We also ran the analysis while defining the market states using prior 24-month market average returns and arrive at similar results. The results are not shown due to limitations of space but are available from the author upon request.

4 Source: National Bureau of Statistics of China (http://www.stats.gov.cn/english/statisticaldata/ yearlydata/).
} 
results from this paper differentiate it from extant empirical studies, such as that of $\mathrm{He}$ and Chen (2006), ${ }^{5}$ by focusing on the market-state-dependent nature of the momentum effect with short-to-intermediate ranking and holding periods (3-12 months) in two market segments, and looking into the driving forces behind the asymmetric patterns of market-state-dependent momentum returns.

The theoretical underpinning of this study originates from Johnson's (2002) seminal work Rational Momentum Effects, where he proposes an enhanced model with an implied potential empirical linkage between the change in market states and the momentum premium. Subsequently, Sagi and Seasholes (2007) propose a theoretical model, suggesting that the UP market condition amplifies the momentum returns while the DOWN market condition causes the deterioration of momentum returns. Under the aegis of this theoretical model, Chordia and Shivakumar (2002) empirically show that the momentum effect is prominent (subdued) during economic expansionary (recessionary) periods. They also postulate that the time-varying risks embedded in a set of common macroeconomic variables ${ }^{6}$ have explanatory power over the momentum effect in the US stock markets. Furthermore, Cooper et al. (2004) categorise market states according to prior 12/24/36-month average market returns and find empirical evidence showing that the significance of the momentum effect is dependent on market states in the US stock markets. Huang (2006) applies Cooper et al.'s (2004) approach in an international setting of seventeen countries ${ }^{7}$ and finds the momentum effect dissipates during time periods following DOWN market state. Among the most recent studies, Stivers and Sun (2009) show that the DOWN (UP) market state, indicated by high (low) cross-sectional stock return dispersion, presages lower (higher) momentum returns in the subsequent period. Wang et al. (2009), Hanauer (2014) and Phua et al. (2010) examine the market-dynamic conditional momentum effect in the Taiwan stock market, Japanese stock market and Australian stock market respectively, and show that the momentum effect persists following the UP-market formation periods, and the market state of formation periods presages the significance of the momentum effect. From a different perspective, Wang and Xu's (2015) study volatility, market states, and momentum effect in the US stock market over April 1953 and June 2009, and find evidence concurring with the aforementioned studies. In the context of the Chinese stock market, He and Chen (2006) analyse the market-state-dependent nature of the momentum effect with very short time window (1-4 weeks) in the UP and DOWN market states over the time period from June 1997 to June 2005, and document that the winner (loser) portfolios are more prone to the momentum effect during the UP (DOWN)-market-state time periods.

\footnotetext{
5 He and Chen (2006) examined the market-state-dependent nature of the momentum effect in very short time windows (1-4 weeks) from June 1997 to June 2005 in the Chinese Class A share market but did not investigate the reasons behind the dynamics of the momentum returns.

6 A set of common macroeconomic variables includes dividend yield, default spread, yield on three-month T-bills, and term-structure spread.

7 The seventeen countries include Australia, Austria, Belgium, Denmark, France, Germany, Hong Kong, Italy, Japan, the Netherlands, Norway, Singapore, Spain, Sweden, Switzerland, the United Kingdom and the United States.
} 
In this study, we find that the momentum returns found in the post-DOWN-market states outpace those found in the post-UP market states for Class A shares listed on both the SHSE and the SZSE for the sample time period from January 1996 to December 2010. Furthermore, the magnitude of the asymmetric pattern of marketstate-dependent momentum returns found in the SHSE outstrips that found in the SZSE. Through the decomposition of the momentum returns following a procedure first proposed by Jegadeesh and Titman (1995), we reveal that the subdued asymmetric pattern of momentum returns found in the SZSE can be attributed to a multitude of factors such as low liquidity, higher market return volatility, and weak under-reaction of share prices to firm-specific news.

The remainder of the paper is organised as follows. Section 2 contains the development of the hypotheses for empirical testing. The dataset employed and the methodological procedures used are portrayed in Sects. 3 and 4, respectively. Section 5 presents the results on the asymmetric patterns of the momentum returns found in the SHSE and SZSE. Lastly, Sect. 6 concludes the paper and explains the theoretical and practical implications.

\section{The Development of the Test Hypotheses}

Following the evidence of the market-state-dependent momentum returns documented by previous scholars, such as Cooper et al. (2004), two hypotheses are tested in this study:

Test hypothesis 1 The asymmetric pattern of the market-state-dependent momentum returns observed among Chinese Class A shares listed on the SHSE is distinct from the pattern found in the SZSE.

This conjecture is built on the unique characteristics of the microstructure of the two exchanges: firstly, the constituents of the SHSE tend to be large and state-owned firms as opposed to the SZSE, which mainly consists of small and export-oriented joint ventures (Wang et al. 2004). Secondly, in terms of total market capitalisation, the SHSE was worth more than twice the SZSE by the end of $2010 .^{8}$ Thirdly, SZSElisted firms are under a looser grip from the central government, indicated by the less concentrated state share ownership ${ }^{9}$ (Xu and Wang 1999). Against this backdrop, shareholders are able to exercise their rights more freely, allowing for a more efficient share price discovery process in the stock exchange (Claessens 1997; Su and Chong 2007). Therefore, we are expecting to find a relatively obscure asymmetric pattern of market-state-dependent momentum returns in the SZSE (Seiler et al. 2005).

Test hypothesis 2 in view of the unique setting of the Chinese equity markets, four factors-market risk, liquidity risk, market volatility, and an under-reaction of share prices towards firm-specific information factors -can potentially be the driving forces

\footnotetext{
8 By the end of 2010, the total market capitalisation of the SHSE was 179,007 (in 100 million RMB) and that of the SZSE stood at 86,415 (in 100 million RMB) (Fact Book SHSE, SZSE 2010).

9 The proportion of foreign investors in the SHSE rose from 1.57 in 2001 to $1.75 \%$ in 2005, and dropped to $0.76 \%$ in 2006 . The proportion of foreign investors in the SZSE increased at a steady pace from 1.55 in 2001 to $2.27 \%$ in 2007 and only dropped a little in the year 2008 to $1.94 \%$ (The SHSE and SZSE Fact Book 2001-2008).
} 
behind the subdued asymmetric pattern of the market-state-dependent momentum effect observed in the SZSE. The contribution of market return volatility towards the momentum returns is more significant in the SHSE.

This conjecture is examined by decomposing the momentum returns found in the SHSE and SZSE using a model augmented with a market risk factor, a liquidity risk factor (Pastor and Stambaugh 2003), a factor indicating the under-reaction of share prices toward firm-specific information (Jegadeesh and Titman 1995), and a market return volatility factor (Wang and Xu 2015). Of these, the market risk factor has long been established as a risk adjustment factor since the conceptualisation of the capital asset pricing model (CAPM) (Sharpe 1964; Treynor 1962). The role of market liquidity risk factor in contributing to the asymmetric market-state-dependent momentum returns is examined because the intricate relationship between liquidity risk factor and expected stock returns in the context of the Chinese stock market has been documented in a few recent studies without conclusive evidence (Chui and Kwok 1998; Nayayan and Zheng 2010). The market return volatility factor is investigated, as Wang and $\mathrm{Xu}$ (2015) find market volatility possesses resilient predictive power over momentum returns in their very recent study. Specifically, they establish the predictive power of market return volatility over momentum returns by showing that "loser stocks are over-sold in volatile markets but over-bought in good market conditions" (p. 86). Their results also show a substantial divergence between the momentum returns achieved during positive and negative market states particularly during high-volatility months. In particular, they postulate that a higher market return volatility signifies a lower contribution of market return volatility towards momentum returns. Given the lower market return volatility associated with the SHSE compared to the SZSE, their finding intrigues us to conjecture whether the contribution of the market return volatility towards momentum returns is more significant in the SHSE and less so in the SZSE. The fundamental differences in the market microstructure, such as market participants, trading volumes, and share ownership between the SHSE and the SZSE, also have a great bearing on motivating us to deploy the three aforementioned risk factors in decomposing momentum returns.

\section{Data}

The sample dataset consists of monthly prices' data ${ }^{10}$ of the Chinese Class A shares listed in the SHSE and the SZSE (excluding interest and dividends which are reinvested automatically). The sample period adopted for the research is from January 1996 to December 2010, entailing 180 months in total. There are 135 months of high volatility $(\mathrm{Vol}+)$, and 45 months of low volatility ( $\mathrm{Vol}-$ ). The sample period is chosen to provide the most recent and comprehensive examination to date of the momentum effect in the Chinese capital market, yet to preclude the potential distortions caused by "the fierce volatility and the low quantity" in the first few years of full operation of the stock market (1991-1995) (He and Tan 2006: p. 1810). There were 855 and 473

\footnotetext{
10 The data are kindly provided by Guotai Junan Securities Co. Ltd. (GTJA) through their database provider Shanghai Wind Information Co., Ltd ( http://www.wind.com.cn/en/Default.aspx).
} 
Table 1 Basic information of the SHSE Class A, and SZSE Class A shares

\begin{tabular}{lllllc}
\hline Indices & Price level $^{\mathrm{a}}$ & Base date & Base point & Sample period & \# of constituents \\
\hline & 2010 & & & & 2010 \\
SHSE Class A & 3277.14 & $21 / 02 / 1991$ & 100 & $01 / 1996-12 / 2010$ & 855 \\
SZSE Class A & 1351.14 & $03 / 04 / 1991$ & 100 & $01 / 1996-12 / 2010$ & 473 \\
\hline
\end{tabular}

Source: The SHSE and SZSE Fact Book 1996-2010

a The unit of price level is point

Table 2 Descriptive statistics of the returns on Class A shares listed on SHSE and SZSE

\begin{tabular}{llllll}
\hline Indices & Mean & Variance & Skewness & Kurtosis & Jarque-Bera \\
\hline SHSE A & 0.00334 & 0.00139 & $-0.05478^{*}$ & $1.46032^{*}$ & $250.67542^{*}$ \\
SZSE A & 0.00519 & 0.00206 & $0.58430 *$ & $2.01168 *$ & $218.30134^{*}$
\end{tabular}

SHSE A represents the returns of all class A stocks listed on the Shanghai Stock Exchange; SZSE A represents the returns of all Class A stocks listed on the Shenzhen Stock Exchange

* Statistically significant at the $10 \%$ level

Class A share stocks trading on the SHSE and the SZSE, respectively, in December 2010. ${ }^{11}$ A self-constructed Class A share Index, ${ }^{12}$ composite index and component index are deployed to portray the statistical characteristics of the monthly share price for stocks trading in the SHSE and SZSE.

Table 1 summarises the basic information of Class A shares listed in the SHSE and SZSE. The index point of the SHSE A shares is valued based on the price of the SHSE A shares on February 21, 1991 (100) and was valued at 3277.14 by the end of 2010, with 855 securities included in total. The SZSE A Index consisted of 473 A share stocks and reached 1351.14 points, calculated based on the market value of the SZSE A stocks on April 3, 1991.

Table 2 describes the statistical attributes of the returns of the Class A shares listed in the SHSE and the SZSE. The SZSE A market fared better, with an average return of 0.0052, while the SHSE A market produced a lacklustre average return of 0.0033 . Despite generating the better average return, the SZSE A market is associated with slightly more risk (0.0021), compared with the risk carried by the SHSE A share market (0.0014). The distribution of the return of the SHSE A market is skewed to the right (-0.0548). Conversely, the return of the SZSE A market shows distributions skewed to the left (0.5843). ${ }^{13}$ As expected in a relatively emergent market, neither set of returns are in line with the pattern of normal distribution indicated by the statistically significant Jarque-Bera statistics.

\footnotetext{
11 Only stocks with at least 60 consecutive observations are included. This mitigates "downward bias of the auto-covariance estimates of small samples" and survivorship bias (Antoniou et al. 2006: p. 842).

12 The overall Class A share Index is a value-weighted index encompassing all the Class A share stocks listed in both the SHSE and the SZSE.

13 The co-skewness risk is controlled for following Ang et al.'s (2006) approach in the results analysis and the results stay robust. See footnote 25 in Sect. 5, empirical results for a more detailed description.
} 


\section{Methodology}

\subsection{Momentum Strategy}

The momentum trading mechanism implemented in this study is largely the same as the procedure documented by Jegadeesh and Titman (1993). Specifically, all the eligible stocks listed in the SHSE and SZSE are ranked based on their R-month $(\mathrm{R}=3$, $6,9,12$ ) average monthly returns in ascending order. The stocks are then put into five portfolios (equally weighted) to form quintile momentum portfolios. The top $20 \%$ stocks are forming the "winner" portfolio, and the bottom $20 \%$ stocks are forming the "loser" portfolio. The zero-cost ${ }^{14}$ momentum portfolios are then held for four different lengths of holding period $\mathrm{H}(\mathrm{H}=3,6,9,12)$. To mitigate the potential issues induced by "bid-ask bounce" bias ${ }^{15}$ and return serial correlation (Arena et al. 2008; Moskowitz and Grinblatt 1999), we skip a month between the end of the ranking period and the start of the holding period (Jegadeesh and Titman 1993; Lehmann 1990). The adoption of the equally-weighted approach imitates layperson's investing behaviours, normally biased due to the " $1 / \mathrm{n}$ heuristic" postulated by Benartzi and Thaler (2001). In rebalancing momentum portfolios, we chose to use a more practical approach ${ }^{16}$ during the holding period-the buy-and-hold strategy - to avoid potentially expensive trading costs in the Chinese stock market (Galariotis et al. 2007).

The calculation of the momentum return $\left(R_{W-L}\right)$ can be mathematically expressed as follows:

$$
R_{W-L}=R_{W}-R_{L}
$$

where $R_{W}$ is the average monthly returns of the "winner" portfolios; and $R_{L}$ is the average monthly returns of the "loser" portfolios.

The statistical significance of the momentum premium can be tested by using t-test statistics:

$$
\frac{\mu_{W}-\mu_{L}}{\sqrt{\frac{\sigma_{W}^{2}}{N_{W}}+\frac{\sigma_{L}^{2}}{N_{L}}}},
$$

where $\mu_{W}$ is the mean monthly return from the "winner" portfolio, $\sigma_{W}^{2}$ is the variance of the "winner" portfolio, $N_{W}$ is the number of stocks in the "winner" portfolio, $\mu_{L}$ represents the mean monthly return on the "loser" portfolio, $\sigma_{L}^{2}$ is the variance of the "loser" portfolio, and $N_{L}$ denotes the number of stocks in the "loser" portfolio (Hon and Tonks 2003).

\footnotetext{
14 Zero-cost strategy is employed for brevity and ease of comparison.

15 The "big-ask bounce" bias is induced by the difference between the bid and ask price for one trade and either the bid or ask price could be chosen for no particular reason as the transaction price during the data collection process (Galariotis et al. 2007).

16 There are two approaches to holding long and short positions during the holding period: (1) rebalancing the holding of long positions on "winner" portfolios and short positions on "loser" portfolios on a monthly basis, which leads to higher than expected trading $\operatorname{costs}^{16}$ (Jegadeesh and Titman 1993); (2) implementing a buy-and-hold strategy throughout the holding period (3, 6, 9, 12 months).
} 
In addition, a methodological procedure used by Cooper et al. (2004) is implemented to analyse the asymmetric patterns of the market-state-dependent momentum returns in the SHSE and the SZSE.

To categorise UP and DOWN market states, we follow Cooper, Gutierrez, and Hameed's (2004) approach ${ }^{17}$ by using a 12-month average market return to differentiate the stock market states (Cooper et al. 2004). ${ }^{18}$ The market returns of the SHSE Class A shares and those of the SZSE Class A shares will be proxied by the returns of the SHSE A share Index and those of the SZSE A share Index, respectively. Mathematically, the procedure can be described by the following two steps:

Step 1: regressing the raw momentum returns against an UP state dummy and a DOWN state dummy.

$$
R_{W-L, t}=R_{W-L, U P} U P_{t}+R_{W-L, D O W N} D O W N_{t}+e_{t},
$$

where $R_{W-L, t}$ denotes the momentum return of different momentum trading strategies (for instance, for a trading strategy with a six-month holding period; $t$ represents the time spot at the end of $\mathrm{t}+6$, and $R_{W-L, t}$ represents the monthly average momentum returns for the holding period from $\mathrm{t}+1$ to $\mathrm{t}+6$ ); $U P_{t}$ is equal to 1 if it is an UP market state (average market return for the previous 12 or 24 months is positive: $R_{\text {market, } t-1, t-k}>0$, where $\mathrm{k}=12$ or 24 ) and is zero otherwise; by the same logic, $D O W N_{t}$ is equal to 1 if it is a DOWN market state (average market return for the previous 12 or 24 months is negative: $R_{\text {market }, t-1, t-k}<0$, where $\mathrm{k}=12$ or 24 ) and is zero otherwise. The average momentum return following an UP market state is denoted by $R_{W-L, U P}$, and the average momentum return following a DOWN market state is symbolised by $R_{W-L, D O W N}$.

Step 2: regressing the raw momentum returns against an UP market state dummy factor.

$$
R_{W-L, t}=\alpha+R_{W-L, U P-D O W N} U P_{t}+e_{t},
$$

where $R_{W-L, U P-D O W N}$ represents the difference of momentum returns under two different market states (Cooper et al. 2004; Du et al. 2009). $U P_{t}$ is the UP market state dummy variable. ${ }^{19}$

\subsection{Measurement of the Liquidity Factor and Market Return Volatility Factor}

Consistent with the measurement of market liquidity proposed by Pastor and Stambaugh (2003), we quantify the monthly liquidity of Class A shares listed in the SHSE

\footnotetext{
17 The results from previous studies in the field have shown that neither macroeconomic factors such as lagged industrial production growth (Huang 2006) nor a combination of macro variables (Cooper et al. 2004; Du et al. 2009) nor even the previous 36-month average market return (Cooper et al. 2004; Huang 2006) is deemed effective in categorising market states.

18 The past 24-month average market return is used as an additional market state definition to check the robustness of the results. This result is available upon request.

19 The variable is 1 if the month is categorised as a post-UP-market state, indicated by the positive prior$12 / 24$ month average market returns $\left(\mathrm{R}_{-}(\right.$market, $\mathrm{t}-1, \mathrm{t}-\mathrm{k})>0$, where $\left.\mathrm{k}=12,24\right)$ and is zero otherwise (post-DOWN-market state).
} 
and those listed in the SZSE by taking equally weighted averages of the liquidity measure of individual Class A stocks listed in the two stock exchanges. ${ }^{20}$ Mathematically, the estimation procedure can be expressed as:

$$
\begin{aligned}
& r_{i, d+1, m}-r_{\frac{S H S E}{S Z S E}, d+1, m}=\alpha_{i, m}+\varphi_{i, m} r_{i, d, m} \\
& \quad+L I Q D_{i, t} \operatorname{sign}\left(r_{i, d, m}-r_{\frac{S H S E}{S Z S E}, d, m}\right) \cdot \omega_{i, d, m}+\epsilon_{i, d+1, \omega}
\end{aligned}
$$

where $r_{i, d, m}$ is the return on stock $\mathrm{i}$ on day $\mathrm{d}$ in month $\mathrm{m} ; r_{\frac{S H S E}{S Z S E}, d, m}$ is the return on the value-weighted market returns of the stocks listed on the SHSE/SZSE on day d in month $\mathrm{m} ; \omega_{i, d, m}$ is the volume (in Yuan) for stocks $\mathrm{i}$ on day $\mathrm{d}$ in month $\mathrm{m}$; and $L I Q D_{i, t}$ is the liquidity measurement for stock i at time point $\mathrm{t}$.

In light of Wang and Xu's (2015) work on the predictive power of market volatility over momentum returns, we employ the lagged 12-month daily return standard deviation to gauge market return volatility (Vol hereafter).

\subsection{Decomposition of Momentum Returns}

In light of the roles that investor over-reaction and under-reaction play in contributing to the momentum returns, a general K-factor model is applied to anatomise the stock returns, factoring in the potential impact of lagged stock returns on the stock returns (Jegadeesh and Titman 1995). Mathematically, it can be expressed as follows:

$$
r_{i, t}=\mu_{i}+\sum_{k=1}^{K}\left(b_{o, i, k}^{t} f_{t, k}+b_{1, i, k}^{t} f_{t-1, k}\right)+e_{i, t},
$$

where $\mu_{i}$ is the unconditional expected return on stock $\mathrm{i} ; f_{t, k}$ is the unexpected kth factor realisation at time point $\mathrm{t} ; b_{0, i, k}^{t}$ is the sensitivity coefficient representing how sensitive the return on stock $i$ is to the contemporaneous realisation of the kth factor at time point $\mathrm{t} ; b_{1, i, k}^{t}$ is the sensitivity coefficient showing how sensitive the return on stock $\mathrm{i}$ is to the lagged realisation of the kth factor at time point $\mathrm{t}$; and $e_{i, t}$ is the estimated firm-specific residual term for stock $\mathrm{i}$ at time point $\mathrm{t}$.

Given the return generating process described in Eq. 6, the momentum returns can be further decomposed as follows:

$$
\begin{aligned}
E(\pi) & =E\left(\frac{1}{N} \sum_{i=1}^{N}\left(r_{i, t-1}-\bar{r}_{m, t-1}\right) r_{i, t}\right) \\
& =\sigma_{\mu}^{2}+\Omega+\sum_{i=1}^{K} \delta_{k} \sigma_{f_{k}}^{2}
\end{aligned}
$$

\footnotetext{
20 The liquidity measure of individual Class A shares is estimated using daily volume data, obtained from the Shanghai Wind Information Co. Ltd.
} 
where

$$
\begin{aligned}
\sigma_{\mu}^{2} & =\frac{1}{N} \sum_{i=1}^{N}\left(\mu_{i}-\bar{\mu}\right)^{2} ; \\
\Omega & \equiv \frac{1}{N} \sum_{i=1}^{N} \operatorname{cov}\left(e_{i, t}, e_{i, t-1}\right) \\
\delta_{t, k} & =\frac{1}{N} \sum_{i=1}^{N}\left(b_{0, i, k}^{t-1}-\bar{b}_{0}^{t}\right)\left(b_{1, i, k}^{t}-\bar{b}_{1}^{t}\right) \\
\delta_{k} & \equiv E\left(\delta_{t, k}\right) .
\end{aligned}
$$

$\bar{b}_{0}^{t}$ and $\bar{b}_{1}^{t}$ denote the cross-sectional averages of $b_{0, i, k}^{t}$ and $b_{1, i, k}^{t}$ respectively. Based on Eq. 7, the decomposition of the momentum returns comprises three parts: (i) $\sigma_{\mu}^{2}=$ $\frac{1}{N} \sum_{i=1}^{N}\left(\mu_{i}-\bar{\mu}\right)^{2}$ represents the cross-sectional variance of the expected returns of the momentum portfolios. The positive association indicates the momentum returns are accentuated by stocks showing superior returns during the ranking and holding time horizon; (ii) $\Omega \equiv \frac{1}{N} \sum_{i=1}^{N} \operatorname{cov}\left(e_{i, t}, e_{i, t-1}\right)$ denotes the average serial covariance of the idiosyncratic component of returns, reflecting the reaction of stock prices towards firmspecific information.; and (iii) $\delta_{t, k}=\frac{1}{N} \sum_{i=1}^{N}\left(b_{0, i, k}^{t-1}-\bar{b}_{0}^{t}\right)\left(b_{1, i, k}^{t}-\bar{b}_{1}^{t}\right)$, where $\delta_{k} \equiv$ $E\left(\delta_{t, k}\right)$ : this factor indicates in which direction and to what extent $\delta_{k}$ is attributable to the differences in the timeliness of stock price reactions to various common factors.

To mitigate the biases induced by the lead-lag structure, the momentum returngenerating processes can be further modified to allow for time-variation in factor sensitivities (Antoniou et al. 2006). The decomposition of the momentum returns can be rewritten accordingly as follows:

$$
E\left(\pi_{t} \mid f_{l, t-1}, e_{i, t-1}\right)=\sigma_{\mu}^{2}+\rho \theta_{t-1}+\sum_{l=1}^{L} \delta_{t} f_{l, t-1}^{2},
$$

where $l$ is the squared demeaned lagged market return $r_{m, t-1}$, the demeaned lagged liquidity factor $L I Q D_{i, t-1}$, and demeaned lagged return market volatility factor $\operatorname{Vol}_{m, t-1}$; and the errors are normally distributed; $\rho=\operatorname{corr}\left(e_{i, t}, e_{i, t-1}\right), \forall i ; \theta_{t}=$ $\frac{1}{N} \sum_{i=1}^{N} e_{i, t}^{2}$.

The market-liquidity factor model is built upon the traditional single-factor (market risk) model in the asset pricing literature. ${ }^{21}$ The construction of the liquidity factor suggests that it measures the liquidity risk-co-movement between returns and unexpected changes in liquidity (Pastor and Stambaugh 2003), reflecting the essence of "order flow". The time-varying sensitivity of the market factor and the liquidity factor towards changes in share prices and the firm-specific factors can be modelled by a

\footnotetext{
21 In light of whether the stock market anomaly-motivated factors such as the HML (value factor) and the SML (size factor) are appropriate risk factors is still highly contentious in the literature, the single-factor model is chosen over other multiple-factor models such as the Fama and French three-factor model (FF3F). Moreover, the value and size factors are generally highly correlated with the liquidity factor as the stocks of firms with small capitalisation tend to be traded thinly, and thus have high book-to-market ratios.
} 
time-series regression as follows:

$$
\begin{aligned}
\pi_{t}= & \beta_{0}+\beta_{1}\left(r_{m, t-1}-\bar{r}_{m}\right)^{2}+\beta_{2}\left(L M H(L I Q D)_{t-1}-\overline{L M H(L I Q D)}\right)^{2} \\
& +\beta_{3}\left(V o l_{t-1}-\overline{V o l}\right)^{2}+\vartheta \theta_{t-1}+u_{t}
\end{aligned}
$$

where $\bar{r}_{m}$ is the common factor of the average market returns and $\overline{L M H(L I Q D)}$ is the monthly average return of portfolios sorted based on the liquidity factor. ${ }^{22}$ The correlation coefficients $\beta_{1}$ and $\beta_{2}$ indicate the delayed contribution of the two factorsmarket returns and the liquidity factor-to the momentum returns. $\beta_{3}\left(V_{o l} l_{t-1}-\overline{V o l}\right)^{2}$ indicates the portion of momentum returns that lagged market return volatility accounts for in percentage terms, where $\mathrm{Vol}$ is the lagged 12-month market (from month $\mathrm{t}-12$ to month $\mathrm{t}-1)$ volatility in percentage terms. $\vartheta \theta_{t-1}\left(\theta_{t}=\frac{1}{N} \sum_{t=1}^{T} \theta_{t-1}\right)$ represents the portion of momentum returns attributable to the under-reaction of share prices toward firm-specific information.

\section{Empirical Results}

\subsection{Class A Shares Listed in the SHSE}

Table 3 reports $^{23}$ the momentum returns of the 16 momentum trading strategies: ${ }^{24}$ those following the UP market state in the SHSE Class A share market in Panel A and those following the DOWN market state ${ }^{25}$ in Panel $B^{26}$ All of the sixteen momentum trading strategies yield positive and statistically significant returns following the UP market state. In comparison, during the time periods following the DOWN market state, five out of the sixteen momentum trading strategies examined produced negative

\footnotetext{
22 Stocks are ranked based on the liquidity measurement (Pastor and Stambaugh 2003), and the LMH is the difference of average returns between portfolios consisting of $20 \%$ stocks with the lowest liquidity and $20 \%$ stocks with the highest liquidity.

23 To boost the power of the tests, we adjusted the momentum returns against Wang and Xu's version of Fama and French's three factors. Specifically, Wang and Xu's version of the FF3F model is augmented by three risk factors-market risk factor $\left(R_{m, t}-R_{f, t}\right)$, firm size effect factor $\left(S M B_{t}\right)$ and a residual free-float ratio $\left(R F F \_H M L_{t}\right)$ (wang and $\left.\mathrm{Xu} 2004\right)$. Compared with the traditional FF3F model, the value effect factor is supplanted by a residual free-float ratio factor, aimed to reflect the strength/quality of firm-level corporate governance in the unique context of the Chinese stock market. The residual free-float ratio is constructed by ranking all the non-financial stocks listed at the end of June each year based on the firms' residual free ratios, estimated by taking the regression of free-float ratios against the logarithm market capitalisation of the corresponding firms, in ascending order. The residual free-float ratio factor is calculated by taking the difference of the returns of high residual free-float ratio portfolios (top 20\%) and those of low residual free-float ratio portfolios (bottom $20 \%$ ). We find that the results of momentum returns stay robust. Some results are presented in "Appendix 3" and the rest are available upon request.

24 In this market segment, there are $104(57.78 \%)$ UP market-state months and $76(42.22 \%)$ DOWNmarket-state months over the sample period (01/1996-12/2010).

25 We also ran the analysis on all the stocks listed in the Chinese Class A share market and found similar results. These results are available upon request.

26 The numbers of UP and DOWN months in the sample period in the SHSE is illustrated in "Appendix 1 ".
} 
Table 3 Momentum returns following UP and DOWN market states for Class A shares listed in the Shanghai Stock Exchange

\begin{tabular}{|c|c|c|c|c|c|}
\hline & & $H=3$ & $H=6$ & $\mathrm{H}=9$ & $\mathrm{H}=12$ \\
\hline \multicolumn{6}{|c|}{ Panel A: Momentum returns Shanghai stock exchange share A (UP market 12 months) } \\
\hline \multirow[t]{3}{*}{$\mathrm{R}=3$} & Q1 & -0.75 & -0.93 & -0.84 & -0.88 \\
\hline & Q5 & 1.26 & 1.8 & 2.02 & 2.17 \\
\hline & Q5-Q1 & $2.01 * *$ & $2.73 * *$ & $2.86^{*}$ & $3.05^{*}$ \\
\hline \multirow[t]{3}{*}{$\mathrm{R}=6$} & Q1 & -0.65 & -0.82 & -0.96 & -0.81 \\
\hline & Q5 & 1.13 & 1.32 & 1.8 & 2.14 \\
\hline & Q5-Q1 & $1.78^{*}$ & $2.14 *$ & $2.76^{*}$ & $2.95 * *$ \\
\hline \multirow[t]{3}{*}{$\mathrm{R}=9$} & Q1 & -0.58 & -0.79 & -0.68 & -0.87 \\
\hline & Q5 & 1.34 & 1.26 & 1.3 & 2.28 \\
\hline & Q5-Q1 & $1.92 *$ & $2.05^{*}$ & $1.98 * *$ & $3.15 * *$ \\
\hline \multirow[t]{3}{*}{$\mathrm{R}=12$} & Q1 & -0.68 & -0.85 & -0.87 & -0.74 \\
\hline & Q5 & 1.05 & 1.17 & 1.32 & 1.79 \\
\hline & Q5-Q1 & $1.73 * *$ & $2.02 * *$ & $2.19 * *$ & 2.53 ** \\
\hline \multicolumn{6}{|c|}{ Panel B: Momentum returns Shanghai stock exchange share A (DOWN market 12 months) } \\
\hline \multirow[t]{3}{*}{$\mathrm{R}=3$} & Q1 & -0.78 & -0.89 & -0.84 & -1.02 \\
\hline & Q5 & -0.73 & -0.81 & -0.72 & -0.87 \\
\hline & Q5-Q1 & 0.05 & $0.08^{*}$ & $0.12 *$ & 0.15 \\
\hline \multirow[t]{3}{*}{$\mathrm{R}=6$} & Q1 & -0.75 & -0.92 & -1.05 & -0.96 \\
\hline & Q5 & -0.73 & -0.88 & -0.98 & -0.86 \\
\hline & Q5-Q1 & $0.02 *$ & $0.04^{*}$ & 0.07 & 0.1 \\
\hline \multirow[t]{3}{*}{$\mathrm{R}=9$} & Q1 & -0.73 & -0.68 & -0.95 & -1.04 \\
\hline & Q5 & -0.81 & -0.7 & -0.9 & -0.95 \\
\hline & Q5-Q1 & -0.08 & -0.02 & $0.05^{*}$ & 0.09 \\
\hline \multirow[t]{3}{*}{$\mathrm{R}=12$} & Q1 & -0.58 & -0.79 & -1.03 & -0.12 \\
\hline & Q5 & -0.68 & -0.86 & -1.07 & -0.06 \\
\hline & Q5-Q1 & -0.1 & $-0.07 *$ & $-0.04 *$ & 0.06 \\
\hline
\end{tabular}

This table presents the momentum returns (the difference between average monthly returns of the "winner" portfolios and those of the "loser" portfolios) following the UP market state and the DOWN market state, as well as the average monthly returns of "winner" and "loser" portfolios in the Class A shares listed in the Shanghai Stock Exchange for the sample period from January 1996 to December 2010. The momentum portfolio formation procedure is akin to the methodology used by Jegadeesh and Titman (1993). At the end of each month during the sample period, all the eligible stocks are ranked in ascending order based on their past R-month (the value of $\mathrm{R}$ denotes the number of months used as ranking period for a specific momentum trading strategy). Q5-Q1 represents the momentum return for each momentum trading strategy. The calculation of the momentum returns following UP and DOWN market states is analogous to the one used by Cooper et al. (2004), Huang (2006), Siganos and Chelley-Steeley (2006) and Du et al. (2009). Mathematically, the procedure can be expressed as $R_{W-L, t}=R_{W-L, U P} U P_{t}+R_{W-L, D O W N} D O W N_{t}+e_{t}$ for ease of comparison. $R_{W-L, t}$ denotes the momentum return at time point $\mathrm{t}$ (for the trading strategy with six-month holding period, t represents the time spot at the end of $\mathrm{t}+6$, and $R_{W-L, t}$ represents the monthly momentum returns for the holding period from $t+1$ to $t+6$ )

* Symbolises statistical significance at the $10 \%$ level

** Symbolises statistical significance at the $5 \%$ level. All the numbers are in percentages 
returns, and the returns of the rest are barely positive, ${ }^{27}$ with only half of these returns statistically significant. ${ }^{28}$

The more pronounced momentum returns found over time periods following the UP market state can be elucidated by a theoretical framework built upon different behavioural theories. For example, given that Asian investors are found to be more overconfident/over-optimistic than their Western counterparts (Yates et al. 1998) on the heels of market run-ups, the investors' euphoric sentiment stokes their confidence/optimism levels (Daniel et al. 1998), amplifying the momentum returns (Antoniou et al. 2013). From a different perspective, the evidence can be interpreted using some experimental psychology evidence-investors, driven by confirmatory bias, emphasise the outcomes that confirm their optimistic predictions following market upswings, and consequently grow overly confident (Griffin and Tversky 1992). This sentiment of overconfidence fuels the over-reactions of the share price and results in the more compelling post-UP-market-state momentum returns (Wu 2011).

Under the two cognitive-system frameworks outlined by Kahneman and Frederick (2002), investors in a buoyant mood are more inclined to rely on the simple intuitive heuristics of System 1 in their decision-making process (Bless and Schwarz 1999; Schwarz 1990). This leads to a more erratic share price, deviating from the share's intrinsic value and consequently underscoring the momentum effect (Barberis et al. 1998; Hong and Stein 1999).

In stark contrast to the evidence of the post-UP-market momentum returns, the postDOWN-market momentum returns (shown in panel B) are all negative and statistically insignificant. This evidence is largely in line with the empirical findings of $\mathrm{He}$ and Chen (2006) in a study on the momentum effect in UP and DOWN markets in the Chinese stock market. ${ }^{29}$

The evidence of a virtually muted momentum effect over time periods following the DOWN market state can be interpreted by various well-established behavioural theories. First, on the heels of a market downdraft, the investors' gloomy mood prompts a systematic processing procedure in the decision-making process (Schwarz 1990; Tiedens and Linton 2001), featured by the use of reflective heuristics such as the neutral, statistical and abstract heuristics of System 2 (Kahenemann and Frederick 2002). The systematic processing mechanism dampens the momentum effect by reducing the occurrence of the under-reaction toward firm-specific news, triggered by investors'

\footnotetext{
27 We control for co-skewness risk by forming quintile portfolios based on their associated co-skewness risk, computed by following Harvey and Siddique (2000). Subsequently, we form quintile portfolios within each quintile portfolio based on stocks' previous performance (3, 6, 9, 12 months). In summary, the average momentum return following the UP market state (SHSE) controlling for co-skewness risk is $2.21 \%$ with Newey-West (1987) t statistics of 3.11; the DOWN market state (SHSE) is: $0.03 \%$ (1.53). The average momentum returns following the UP market state (SZSE) controlling for co-skewness risk is $0.43 \%$ (1.38); the DOWN market state (SZSE) is: $-0.86 \%$ (-2.05). This evidence suggests that the market-statedependent momentum returns found in this study are not driven by co-skewness risk.

28 For a Class A share transactions, investors have to pay $0.3 \%$ of trading value as commission to securities firms and $0.1 \%$ of trading value as a transfer fee to the Depository \& Clearing company. Sell-side investors are required to pay $0.1 \%$ of trading value as stamp duty to the tax authorities.

29 The asymmetry of the market-dependent momentum returns found in this research concur with the evidence found by Cooper et al. (2004) on the US stock markets, Huang (2006) on a group of international stock markets and Du et al. (2009) on the Taiwanese stock market.
} 
heuristic biases such as overconfidence (Daniel et al. 1998) and conservatism (Barberis et al. 1998). At the other end of the spectrum, following a market skid, investors grow slightly more confident in expecting the occurrence of a reversal-a market runup. This perception deludes them into thinking that the market has found its technical bottom (Shefrin 2000) and consequently undermines the momentum effect under the framework of the investors' hesitation behavioural model (Du 2002).

\subsection{Class A Shares Listed in the SZSE}

Class $^{30}$ A shares listed in the SZSE have been historically different compared to Class A shares listed in the SHSE in their quantity, liquidity level, and market capitalisation. The different features of the SHSE intrigue us enough to investigate any evidence of the asymmetric pattern of market-state-dependent momentum returns. ${ }^{31}$ in this market segment

Table 4 summarises the momentum returns of 16 different momentum trading strategies for the time periods following the UP market state in Panel A and the post-DOWN-market momentum returns in Panel B over the sample time period from January 1996 to December 2010. In Panel A, the majority of momentum returns (11 out of 16 momentum trading strategies) are positive and statistically significant, manifesting the superior performance of the post-UP-market momentum strategies.

The evidence of the post-DOWN-market momentum returns across 16 different momentum trading strategies is presented in Panel B of Table 4. Specifically, all the momentum returns are negative and statistically insignificant, striking a contrast with the evidence of post-UP-market momentum returns. ${ }^{32}$

\subsection{The Comparison of the Asymmetric Patterns of Momentum Returns in the SHSE and SZSE}

Table 5 summarises the differences in market-state-dependent momentum returns found in the SHSE and SZSE. The asymmetric patterns are statistically significant on both market segments across all the momentum trading strategies, with the post-UPmarket momentum returns outstripping the post-DOWN-market momentum returns. Furthermore, compared to the SHSE, there is a relatively subdued asymmetric pattern of market-state-dependent momentum returns in the SZSE, which echoes the expectation implied by test hypothesis 1 . This evidence could be the result of a couple of factors: firstly, lower liquidity ${ }^{33}$ and the absence of negative associations between

\footnotetext{
30 The number of UP and DOWN months over the sample period in the SZSE is illustrated in "Appendix 2".

31 In this market segment, there are $101(56.11 \%)$ UP-market-state months and $79(43.89 \%)$ DOWNmarket-state months over the sample period (January 1996-December 2010).

32 The equality test result shows that most of the differences between the momentum returns found following the UP- and DOWN-market states in the SZSE are statistically significant, and this is available upon request.

33 On average, the SHSE has 1.3 times the turnover ratios of the SZSE over the sample time period (the SHSE and SZSE Fact Book 2001-2010).
} 
Table 4 Momentum returns following UP and DOWN market states for Class A shares listed in the Shenzhen Stock Exchange

\begin{tabular}{|c|c|c|c|c|c|}
\hline & & $\mathrm{H}=3$ & $\mathrm{H}=6$ & $\mathrm{H}=9$ & $\mathrm{H}=12$ \\
\hline \multicolumn{6}{|c|}{ Panel A: Momentum returns Shenzhen stock exchange share A (UP market 12 months) } \\
\hline \multirow[t]{3}{*}{$\mathrm{R}=3$} & Q1 & -1.36 & -0.89 & -0.95 & -1.04 \\
\hline & Q5 & -1.4 & -0.83 & 0.09 & 0.21 \\
\hline & Q5-Q1 & $-0.04 *$ & $0.06^{*}$ & $1.04 *$ & $1.25^{*}$ \\
\hline \multirow[t]{3}{*}{$R=6$} & Q1 & -0.47 & -0.38 & -0.42 & -0.39 \\
\hline & Q5 & -0.55 & -0.36 & 0.36 & 0.79 \\
\hline & Q5-Q1 & -0.08 & $0.02 *$ & $0.78^{*}$ & 1.18 \\
\hline \multirow[t]{3}{*}{$\mathrm{R}=9$} & Q1 & -0.17 & -0.35 & -0.26 & -0.27 \\
\hline & Q5 & -0.24 & -0.34 & 0.38 & 0.78 \\
\hline & Q5-Q1 & $-0.07 *$ & $0.01 *$ & $0.64^{* *}$ & $1.05^{*}$ \\
\hline \multirow[t]{3}{*}{$\mathrm{R}=12$} & Q1 & -0.35 & -0.29 & -0.17 & -0.08 \\
\hline & Q5 & -0.48 & -0.34 & 0.42 & 0.84 \\
\hline & Q5-Q1 & -0.13 & $-0.05^{*}$ & $0.59 * *$ & $0.92^{*}$ \\
\hline \multicolumn{6}{|c|}{ Panel B: Momentum returns Shenzhen stock exchange share A (DOWN market 12 months) } \\
\hline \multirow[t]{3}{*}{$\mathrm{R}=3$} & Q1 & -0.16 & -0.27 & -0.36 & -0.41 \\
\hline & Q5 & -1.41 & -1.33 & -1.17 & -1.08 \\
\hline & Q5-Q1 & -1.25 & -1.06 & -0.81 & -0.67 \\
\hline \multirow[t]{3}{*}{$\mathrm{R}=6$} & Q1 & -0.34 & -0.28 & -0.31 & -0.19 \\
\hline & Q5 & -1.66 & -1.45 & -1.1 & -0.77 \\
\hline & Q5-Q1 & -1.32 & $-1.17^{*}$ & -0.79 & -0.58 \\
\hline \multirow[t]{3}{*}{$\mathrm{R}=9$} & Q1 & -0.18 & -0.34 & -0.26 & -0.31 \\
\hline & Q5 & -1.59 & -1.4 & -1.01 & -0.82 \\
\hline & Q5-Q1 & $-1.41^{*}$ & -1.06 & -0.75 & -0.51 \\
\hline \multirow[t]{3}{*}{$\mathrm{R}=12$} & Q1 & -0.32 & -0.27 & -0.35 & -0.26 \\
\hline & Q5 & -1.76 & -1.54 & -1.07 & -0.74 \\
\hline & Q5-Q1 & -1.44 & -1.27 & -0.72 & -0.48 \\
\hline
\end{tabular}

This table presents the momentum returns (the difference between average monthly returns of the "winner" portfolios and those of the "loser" portfolios) following the UP market state and the DOWN market state as well as the average monthly returns of the "winner" and the "loser" portfolios in the Class A share listed in the Shenzhen Stock Exchange for the sample period from January 1996 to December 2010. The detailed description of the methodology is referred to in the notes below Table 3

liquidity and cross-sectional stock returns in the SZSE (Narayan and Zheng 2011) suggest that there are fewer irrational investors in the market segment (Baker and Stein 2004). Consequently, in the SZSE, the investors' decision-making process is subject to less influence from heuristic biases such as overreaction (Jiang et al. 2011; Wu 2011) and underconfidence (Du 2002). The dwindling irrational behaviours may have curtailed the asymmetric pattern of market-state-dependent momentum returns in the SZSE. 
Table 5 Comparison between the asymmetric patterns of market-state-dependent momentum returns in the SHSE and SZSE

\begin{tabular}{lllllllll}
\hline & $(3,3)$ & $(3,6)$ & $(3,9)$ & $(3,12)$ & $(6,3)$ & $(6,6)$ & $(6,9)$ & $(6,12)$ \\
\hline SHSE & 1.96 & 2.65 & 2.74 & 2.9 & 1.76 & 2.1 & 2.69 & 2.85 \\
t stats & 2.31 & 4.08 & 3.36 & 2.19 & 3.55 & 2.74 & 3.08 & 4.27 \\
SZSE & 2 & 2.07 & 1.93 & 3.06 & 1.83 & 2.09 & 2.23 & 2.47 \\
t stats & 3.05 & 2.17 & 3.66 & 2.14 & 1.53 & 1.82 & 1.38 & 2.08 \\
\hline & $(9,3)$ & $(9,6)$ & $(9,9)$ & $(9,12)$ & $(12,3)$ & $(12,6)$ & $(12,9)$ & $(12,12)$ \\
& 1.21 & 1.12 & 1.85 & 1.92 & 1.24 & 1.19 & 1.57 & 1.76 \\
SHSE & 2.51 & 3.66 & 4.17 & 3.84 & 2.91 & 3.35 & 4.06 & 3.9 \\
t stats & 1.34 & 1.07 & 1.39 & 1.56 & 1.31 & 1.22 & 1.31 & 1.4 \\
SZSE & 2.84 & 3.05 & 3.47 & 4.02 & 2.52 & 1.37 & 2.53 & 2.46 \\
t stats & 2.02 &
\end{tabular}

This table reports the difference between the momentum returns following UP and DOWN market states in the Class A share market for sixteen different momentum trading strategies. The difference is estimated by regressing the raw momentum returns against an UP dummy variable $\left(U P_{t}\right)$ and an intercept $(\alpha)$, following the same methodology for equality tests used by Cooper et al. (2004) and Du et al. (2009). Mathematically, it can be written as $R_{W-L, t}=\alpha+R_{W-L, U P-D O W N} U P_{t}+e_{t}$, where $R_{W-L, t}$ denotes the momentum return at time point $\mathrm{t}$ (for the trading strategy with six-month holding period, t represents the time spot at the end of $\mathrm{t}+6$, and $R_{W-L, t}$ represents the monthly momentum returns for the holding period from $\mathrm{t}+1$ to $\mathrm{t}+6)$

Secondly, foreign institutional investors tend to have an advantage over domestic investors in acquiring share-price-determining information in the SHSE (Yang 2003). In contrast, in the SZSE, information tends to flow from domestic retail investors to foreign institutional investors (Sjöö and Zhang 2000), suggesting that the domestic investors are more involved in the asset price discovery process (Chan et al. 2007). Consequently, the more efficient asset price discovery process curtails the underreaction of share prices towards firm-specific information, leading to the more subdued asymmetric pattern of market-state-dependent momentum returns in the SZSE.

\subsection{The Decomposition of Momentum Returns}

Through decomposing the state-dependent momentum returns, ${ }^{34}$ we aim to examine the contributions of the market risk factor, liquidity factor, and the under-reaction of share prices towards firm-specific information to the momentum returns in the two stock exchanges.

Tables 6 and 7 report the estimated average stock return sensitivities to the market factor and liquidity factor in the SHSE and SZSE, respectively. Mathematically, the

\footnotetext{
34 Given the robustness of the evidence found in the two stock exchanges, we only focus on a 6-month ranking period and a 6-month holding period.
} 
Table 6 Estimated stock-return sensitivities ( 3 factors-SHSE)
The coefficients $\bar{b}_{0, f}$ and $\bar{b}_{1, f}$, where $f=M, L I Q D$, are estimated by running time-series regression on the equation $r_{i, t}=$ $\alpha_{i}+b_{0, m} r_{m, t}+b_{1, m} r_{m, t-1}+$ $b_{0, L I Q D} L M H(L I Q D)_{t}+$ $b_{1, L I Q D L M H(L I Q D)_{t-1}+}$ $e_{i, t}$. LHM(LIQD) is the difference between the return on a portfolio of least liquid stocks and the return on a portfolio of most liquid stocks. The regression was performed on both sub-samples and whole sample (all stocks). $\bar{b}_{0, f}$ and $\bar{b}_{1, f}$ are the averages of $b_{0, f}$ and $b_{1, f}$

* Indicates statistical significance at the $10 \%$ level ** Indicates statistical significance at the $5 \%$ level

\begin{tabular}{|c|c|c|c|}
\hline & $\bar{b}_{0, M}$ & $\bar{b}_{1, M}$ & $\hat{\delta}_{M}$ \\
\hline Smallest stocks & $\begin{array}{l}0.368 \\
(10.871)^{*}\end{array}$ & $\begin{array}{l}0.597 \\
(28.365)^{*}\end{array}$ & 0.029 \\
\hline Small stocks & $\begin{array}{l}0.324 \\
(15.762)^{*}\end{array}$ & $\begin{array}{l}0.503 \\
(30.681)^{*}\end{array}$ & 0.034 \\
\hline Medium stocks & $\begin{array}{l}0.3 \\
(37.851)^{*}\end{array}$ & $\begin{array}{l}0.514 \\
(50.735)^{*}\end{array}$ & 0.025 \\
\hline Large stocks & $\begin{array}{l}0.315 \\
(38.792)^{*}\end{array}$ & $\begin{array}{l}0.518 \\
(40.017) *\end{array}$ & 0.016 \\
\hline Largest stocks & $\begin{array}{l}0.372 \\
(20.718)^{*}\end{array}$ & $\begin{array}{l}0.548 \\
(35.678)^{*}\end{array}$ & 0.003 \\
\hline $\begin{array}{l}\text { Average } \\
\text { All stocks }\end{array}$ & $\begin{array}{l}0.336 \\
0.342 \\
(34.718)^{*}\end{array}$ & $\begin{array}{l}0.536 \\
0.574 \\
(53.816)^{*}\end{array}$ & $\begin{array}{l}0.021 \\
0.0006\end{array}$ \\
\hline & $\bar{b}_{0, L I Q D}$ & $\bar{b}_{1, L I Q D}$ & $\hat{\delta}_{L I Q D}$ \\
\hline Smallest stocks & $\begin{array}{l}0.315 \\
(14.786)^{*}\end{array}$ & $\begin{array}{l}0.582 \\
(10.183)^{*}\end{array}$ & 0.183 \\
\hline Small stocks & $\begin{array}{l}0.274 \\
(7.937)^{*}\end{array}$ & $\begin{array}{l}0.466 \\
(8.015)^{*}\end{array}$ & 0.137 \\
\hline Medium stocks & $\begin{array}{l}0.283 \\
(10.173)^{*}\end{array}$ & $\begin{array}{l}0.489 \\
(9.275)^{*}\end{array}$ & 0.105 \\
\hline Large stocks & $\begin{array}{l}0.206 \\
(8.704)^{*}\end{array}$ & $\begin{array}{l}0.461 \\
(10.165)^{*}\end{array}$ & 0.128 \\
\hline Largest stocks & $\begin{array}{l}0.158 \\
(8.106)^{*}\end{array}$ & $\begin{array}{l}0.352 \\
(6.815)^{*}\end{array}$ & 0.104 \\
\hline Average & 0.247 & 0.470 & 0.131 \\
\hline All stocks & $\begin{array}{l}0.306 \\
(10.135)^{*}\end{array}$ & $\begin{array}{l}0.522 \\
(8.103)^{*}\end{array}$ & 0.085 \\
\hline
\end{tabular}

decomposition procedure can be expressed as:

$$
\begin{aligned}
r_{i, t}= & \alpha_{i}+b_{0, m} r_{m, t}+b_{1, m} r_{m, t-1}+b_{0, L I Q D} L M H(L I Q D)_{t} \\
& +b_{1, L I Q D} L M H(L I Q D)_{t-1}+e_{i, t}
\end{aligned}
$$

This procedure disregards the time-varying property of the coefficients, and focuses on the relationship between the momentum returns and the contemporaneous and lagged factor realisations (market and liquidity factors). As shown in Tables 6 and 7, all the stocks listed in the SHSE and SZSE are sorted into different groups based on their market capitalisation. Across different groups of stocks with different sizes of market capitalisation, the contemporaneous (lagged) market factors ( $\bar{b}_{0, M}$ and $\left.\bar{b}_{1, M}\right)$ averaged out at $0.336(0.536)$ for the stocks listed in the SHSE and 0.352(0.652) in 
Table 7 Estimated stock-return sensitivities (3 factors-SZSE)

\begin{tabular}{|c|c|c|c|c|}
\hline $\begin{array}{l}\text { Table } 7 \text { Estimated stock-return } \\
\text { sensitivities ( } 3 \text { factors-SZSE) }\end{array}$ & & $\bar{b}_{0, M}$ & $\bar{b}_{1, M}$ & $\hat{\delta}_{M}$ \\
\hline & Smallest stocks & 0.371 & 0.713 & 0.018 \\
\hline & & $(15.673)^{*}$ & $(23.858)^{*}$ & \\
\hline & Small stocks & 0.342 & 0.626 & 0.025 \\
\hline & & $(16.782)^{*}$ & $(30.416) *$ & \\
\hline & Medium stocks & 0.356 & 0.614 & 0.011 \\
\hline & & $(22.518)^{*}$ & $(25.314)^{*}$ & \\
\hline & Large stocks & 0.339 & 0.608 & 0.009 \\
\hline & & $(40.581)^{*}$ & $(17.815)^{*}$ & \\
\hline & Largest stocks & 0.351 & 0.685 & 0.002 \\
\hline & & $(20.517)^{*}$ & $(27.641)^{*}$ & \\
\hline & Average & 0.352 & 0.649 & 0.013 \\
\hline & All stocks & 0.348 & 0.652 & 0.004 \\
\hline & & $(30.616)^{*}$ & $(25.863)^{*}$ & \\
\hline & & $\bar{b}_{0, L I Q D}$ & $\bar{b}_{1, L I Q D}$ & $\hat{\delta}_{L I Q D}$ \\
\hline & Smallest stocks & 0.336 & 0.659 & 0.132 \\
\hline & & $(15.387)^{*}$ & $(12.562)^{*}$ & \\
\hline & Small stocks & 0.307 & 0.628 & 0.105 \\
\hline & & $(8.941)^{*}$ & $(10.471)^{*}$ & \\
\hline & Medium stocks & 0.315 & 0.617 & 0.089 \\
\hline & & $(7.572)^{*}$ & $(11.371)^{*}$ & \\
\hline & Large stocks & 0.298 & 0.587 & 0.095 \\
\hline & & $(6.521)^{*}$ & $(3.481)^{* *}$ & \\
\hline & Largest stocks & 0.236 & 0.599 & 0.036 \\
\hline & & $(8.191)^{*}$ & $(9.0460)^{*}$ & \\
\hline & Average & 0.298 & 0.618 & 0.091 \\
\hline & All stocks & 0.316 & 0.658 & 0.052 \\
\hline 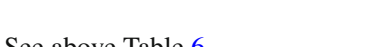 & & $(13.105)^{*}$ & $(12.385)^{*}$ & \\
\hline
\end{tabular}

See above Table 6

the SZSE. These results indicate that the momentum returns react more to the lagged market factor than the contemporaneous one, contrasting the evidence found in the UK stock market (Antoniou et al. 2006). The bottom panels of Tables 6 and 7 present the sensitivities of contemporaneous (lagged) liquidity factors to the momentum returns in the two stock exchanges, respectively. On average, the estimated coefficient of the contemporaneous (lagged) liquidity factors stands at 0.247 (0.470) for the SHSE and $0.298(0.618)$ for the SZSE. Noticeably, in line with the findings on the estimated sensitivities to the market factor realisation, the momentum returns are more sensitive in responding to the changes in the lagged liquidity factor across all groups of stocks listed on the two stock exchanges. Comparing the results reported in Tables 6 and 7 side by side, the estimated coefficients suggest that on average, the momentum returns are more heavily influenced by the lagged market factor and the lagged liquidity factor in the SZSE than in the SHSE. 
Table 8 The decomposition of momentum returns (four factors-SHSE)

\begin{tabular}{|c|c|c|c|c|c|}
\hline & $\hat{\delta} \sigma_{M}^{2} \times 10^{3}$ & $\hat{\delta} \sigma_{L I Q D}^{2} \times 10^{3}$ & $\hat{\delta} \sigma_{V o l}^{2} \times 10^{3}$ & $\Omega \times 10^{3}$ & $\hat{\delta} \sigma_{\alpha}^{2} \times 10^{3}$ \\
\hline Smallest stocks & 2.843 & 4.382 & 6.104 & 9.318 & 1.047 \\
\hline Small stocks & 2.631 & 5.106 & 5.792 & 8.435 & 1.316 \\
\hline Medium stocks & 2.017 & 5.217 & 5.581 & 8.195 & 1.016 \\
\hline Large stocks & 1.825 & 5.482 & 5.271 & 7.782 & 0.974 \\
\hline Largest stocks & 1.779 & 6.183 & 4.899 & 7.108 & 1.202 \\
\hline All stocks & 2.547 & 5.063 & 5.425 & 8.572 & 1.185 \\
\hline Proportions & $11.18 \%$ & $22.21 \%$ & $23.80 \%$ & $37.61 \%$ & $5.20 \%$ \\
\hline \multicolumn{6}{|c|}{$\begin{array}{l}\text { This table summarises the results from running the time-se } \\
b_{0, m} r_{m, t}+b_{1, m} r_{m, t-1}+b_{0, L I Q D} L M H(L I Q D)_{t}+b_{1, L I Q D} L M \\
b_{1, V o l} V o l_{m . t-1}+e_{i, t} \text {. The term } \hat{\delta} \sigma_{M}^{2} \text { estimates the extent to which the } \\
\text { to the reaction of share price towards market movements; } \hat{\delta} \sigma_{L I Q D}^{2} \\
\text { momentum returns attributable to the reaction of share prices to the lic } \\
\text { portion of momentum returns that lagged market return volatility acc } \\
\Omega=\frac{1}{N} \sum_{i=1}^{N} \operatorname{cov}\left(e_{i, t}, e_{i, t-1}\right) \text { is the average autocovariance of the } \\
\text { mated momentum returns attributable to the underreaction of share pric } \\
\text { cross-sectional variance of expected returns }\left(\sigma_{\alpha}^{2}\right) \text { indicates the part of } \\
\text { Table } 9 \text { The decomposition of momentum returns (4 factors-SZSE) }\end{array}$} \\
\hline & $\hat{\delta} \sigma_{M}^{2} \times 10^{3}$ & $\hat{\delta} \sigma_{L I Q D}^{2} \times 10^{3}$ & $\hat{\delta} \sigma_{V o l}^{2} \times 10^{3}$ & $\Omega \times 10^{3}$ & $\hat{\delta} \sigma_{\alpha}^{2} \times 10^{3}$ \\
\hline Smallest stocks & 0.015 & 0.029 & 0.153 & 0.215 & 0.012 \\
\hline Small stocks & 0.023 & 0.031 & 0.146 & 0.225 & 0.014 \\
\hline Medium stocks & 0.029 & 0.031 & 0.142 & 0.228 & 0.016 \\
\hline Large stocks & 0.032 & 0.033 & 0.139 & 0.231 & 0.014 \\
\hline Largest stocks & 0.041 & 0.036 & 0.135 & 0.235 & 0.016 \\
\hline All stocks & 0.028 & 0.030 & 0.141 & 0.218 & 0.014 \\
\hline Proportions & $6.50 \%$ & $6.96 \%$ & $32.72 \%$ & $50.58 \%$ & $3.25 \%$ \\
\hline
\end{tabular}

See above Table 8

Tables 8 and 9 report the estimated portions of the momentum return attributable to market risk, liquidity risk, market return volatility, and the under-reaction of stock prices towards firm-specific news based on the decomposition procedure, which can be expressed as:

$$
\begin{aligned}
& r_{i, t}=\alpha_{i}+b_{0, m} r_{m, t}+b_{1, m} r_{m, t-1}+b_{0, L I Q D} L M H(L I Q D)_{t} \\
& +b_{1, L I Q D} L M H(L I Q D)_{t-1}+b_{0, V_{o l}} V_{o l} l_{m, t}+b_{1, V o l} V_{o l} l_{m-1}+e_{i, t}
\end{aligned}
$$

In the SHSE, market risk, market return volatility, and the under-reaction of stock prices to firm-specific news accounts for slightly larger momentum returns for the groups of stocks with small capitalisation than those associated with larger capitalisation 
(market risk: 2.843 versus 1.779; market return volatility: 6.104 versus 4.899; shareprice under-reaction to firm-specific news: 9.318 versus 7.108$)$. On the other hand, the contribution of the liquidity factor is markedly more significant among stocks with the large capitalisation in the same stock exchange. In stark contrast, there is no evidence showing similar division in terms of the contributions to the momentum returns across stocks with various sizes of market capitalisation in the SZSE. The last rows of the two results tables list out the proportions of each factor contributing to the momentum returns among all stocks listed in the SHSE and SZSE. The evidence suggests that in comparison to the SHSE, liquidity risk matters substantially less, while the market return volatility and the share-price under-reaction to firm-specific news jointly play a significantly more salient role (over $80 \%$ ) in forming the momentum returns in the SZSE.

Allowing pertinent factors to vary over time, the momentum returns are decomposed through running time-series regression $\pi_{t}=\beta_{0}+\beta_{1}\left(r_{m, t-1}-\bar{r}_{m}\right)^{2}+$ $\beta_{2}\left(L M H(L I Q D)_{t-1}-\overline{L M H(L I Q D)}\right)^{2}+\beta_{3}\left(V o l_{t-1}-\overline{V o l}\right)^{2}+\vartheta \theta_{t-1}+u_{t}$ (Eq. 9). The results are reported in Tables 10 and 11, where Panel A shows the estimated regression coefficients and Panel B shows the estimated contributions of each component to the momentum returns, respectively. The coefficients, $\beta_{1}, \beta_{2}, \beta_{3}$ and $\vartheta$, are mostly positive and statistically significant (at either the 10-percent or 5-percent significance level) across different groups of stocks, indicating that all four factors (market, liquidity, market return volatility and the share-price under-reaction to firmspecific news) contribute to the momentum returns in a positive way. Looking into the magnitude of momentum returns shown in the last row of Panel B, the four components seem to influence the momentum returns in the SHSE and the SZSE in distinct manners. In the SHSE, the lion's share of the momentum returns is attributable to market return volatility $(39.19 \%)$ and share-price under-reaction to the firm-specific news component $(41.73 \%)$. In contrast, the market risk component and market return volatility appear to account for the majority of the momentum returns in the SZSE (40.71 and $14.16 \%$, respectively). With factor sensitivities varying over time, the liquidity component contributes to a slightly larger portion of the momentum returns in the SZSE compared to the SHSE (SZSE: 17.70\%; SHSE: 13.29\%). In line with the prediction outlined in hypothesis 2 and Wang and Xu's (2015) finding, we find the contribution of market return volatility towards momentum returns is more significant in the SHSE (SHSE: 39.19\%; SZSE: 27.43\%). Overall, this evidence corroborates the claim outlined in test hypothesis 2 that the relatively subdued liquidity in the SZSE and the lack of support from the market return volatility and under-reaction of share prices to firm-specific news would give rise to a subdued asymmetric pattern of market-state-dependent momentum returns in the SZSE.

\section{Concluding Remarks}

This study offers empirical findings on the asymmetric patterns of market-statedependent momentum returns in two different market segments of the Chinese stock market-the Class A shares listed in the SHSE and the Class A shares listed in the 
Table 10 The decomposition of momentum returns with time-varying factor sensitivities (4 factors-SHSE)

\begin{tabular}{llllll}
\hline & $\beta_{0} \times 10^{3}$ & $\beta_{1} \times 10^{3}$ & $\beta_{2} \times 10^{3}$ & $\beta_{3} \times 10^{3}$ & $\vartheta \times 10^{3}$ \\
\hline Panel A: Estimated coefficients & & & & \\
Smallest stocks & 0.021 & 18.527 & 48.217 & 30.517 & 16.286 \\
& 0.521 & $(3.016)^{* *}$ & $(2.063)^{* *}$ & $(3.041)^{* *}$ & $(3.013)^{*}$ \\
Small stocks & 0.026 & 20.152 & 50.198 & 32.638 & 18.173 \\
& 0.817 & $(4.215)^{* *}$ & $(3.755)^{* *}$ & $(3.153)^{* *}$ & $(2.013)^{*}$ \\
Medium stocks & 0.03 & 21.074 & 52.173 & 35.103 & 20.437 \\
& 1.012 & $(2.553)^{*}$ & $(5.016)^{* *}$ & $(4.102)^{* *}$ & $(2.843)^{*}$ \\
Large stocks & 0.032 & 24.163 & 54.183 & 38.105 & 24.373 \\
Largest stocks & $(2.011)^{*}$ & $(3.016)^{* *}$ & $(4.027)^{* *}$ & $(3.016)^{* *}$ & $(3.051)^{*}$ \\
All stocks & 0.045 & 24.537 & 58.936 & 40.155 & 28.904 \\
& $(2.531)^{* *}$ & $(3.012)^{* *}$ & $(4.196)^{* *}$ & $(3.026)^{* *}$ & $(3.158)^{*}$ \\
\hline & 0.031 & 22.538 & 51.846 & 36.173 & 25.014 \\
& $(2.016)^{* *}$ & $(3.016)^{* *}$ & $(3.621)^{*}$ & $(4.051)^{* *}$ & $(3.174)^{*}$ \\
\hline
\end{tabular}

\begin{tabular}{lllll}
\multicolumn{2}{l}{ Panel B: Contribution to the momentum returns } & & \\
Smallest stocks & 2.163 & 4.846 & 10.284 & 12.374 \\
& $(2.011)^{*}$ & $(2.015)^{*}$ & $(4.012)^{* *}$ & $(2.635)^{* *}$ \\
Small stocks & 2.053 & 5.016 & 12.036 & 13.427 \\
& $(2.044)^{*}$ & $(2.014)^{*}$ & $(3.168)^{* *}$ & $(3.015)^{*}$ \\
Medium stocks & 1.859 & 5.257 & 14.274 & 15.438 \\
& $(2.131)^{*}$ & $(3.011)^{* *}$ & $(3.107)^{* *}$ & $(4.153)^{* *}$ \\
Large stocks & 2.043 & 6.829 & 15.372 & 17.273 \\
& 1.738 & $(2.015)^{*}$ & $(3.048)^{* *}$ & $(3.152)^{*}$ \\
Largest stocks & 2.407 & 6.382 & 17.264 & 16.183 \\
& $(2.522)^{*}$ & $(2.843)^{*}$ & $(4.552)^{* *}$ & $(4.012)^{* *}$ \\
All stocks & 2.258 & 5.183 & 15.283 & 16.273 \\
& $(2.753)^{*}$ & $(2.513)^{*}$ & $(3.726)^{* *}$ & $(4.015)^{* *}$ \\
Proportions & $5.79 \%$ & $13.29 \%$ & $39.19 \%$ & $41.73 \%$
\end{tabular}

The coefficients, i.e. $\beta_{1} \beta_{2} \beta_{3}$, and $v$, are estimated based on $\pi_{t}=\beta_{0}+\beta_{1}\left(r_{m, t-1}-\bar{r}_{m}\right)^{2}+$ $\beta_{2}\left(L M H(L I Q D)_{t-1}-L M H(L I Q D)\right)^{2}+\beta_{3}\left(V o l_{t-1}-\overline{V o l}\right)^{2}+\vartheta \theta_{t-1}+u_{t} . \theta$ is obtained from the equation: $\theta_{t}=\frac{1}{N} \sum_{i=1}^{N} e_{i, t}^{2} . e_{i, t}$ is the residual from the time-series regression $r_{i, t}=\alpha_{i}+b_{0, m} r_{m, t}+$ $b_{1, m} r_{m, t-1}+b_{0, L I Q D} L M H(L I Q D)_{t}+b_{1, L I Q D} L M H(L I Q D)_{t-1}+e_{i, t}$. The estimated contributions of the market factor, the liquidity factor, and the market return volatility factor are represented by the product of the coefficient and corresponding variances of the factor from the regression $\left(\beta_{1} \sigma_{M}^{2}, \beta_{2} \sigma_{L I Q D}^{2}\right.$, and $\left.\beta_{3} \sigma_{V o l}^{2}\right) . v\left(\frac{1}{T} \sum_{i=1}^{T} \theta_{i-1}\right)$ measures the portion of the momentum returns attributable to the underreaction of share price towards firm-specific news

* Indicates significance at the $10 \%$ level

** At the 5\% level 
Table 11 The decomposition of momentum returns with time-varying sensitivities (4 factors-SZSE)

\begin{tabular}{|c|c|c|c|c|c|}
\hline & $\beta_{0} \times 10^{3}$ & $\beta_{1} \times 10^{3}$ & $\beta_{2} \times 10^{3}$ & $\beta_{3} \times 10^{3}$ & $\vartheta \times 10^{3}$ \\
\hline \multicolumn{6}{|c|}{ Panel A: Estimated coefficients } \\
\hline \multirow[t]{2}{*}{ Smallest stocks } & 0.049 & 30.528 & 40.268 & 24.184 & 18.372 \\
\hline & 1.058 & $(3.105)^{*}$ & $(2.025)^{*}$ & $(2.016)^{*}$ & $(2.015)^{* *}$ \\
\hline \multirow[t]{2}{*}{ Small stocks } & 0.052 & 32.053 & 43.692 & 27.184 & 15.372 \\
\hline & 1.583 & $(2.153)^{*}$ & $(2.015)^{*}$ & $(3.018)^{*}$ & $(2.069)^{*}$ \\
\hline \multirow[t]{2}{*}{ Medium stocks } & 0.046 & 36.173 & 42.051 & 25.438 & 19.275 \\
\hline & 1.372 & $(3.044)^{*}$ & $(2.684)^{*}$ & $(2.854)^{* *}$ & $(2.835)^{*}$ \\
\hline \multirow[t]{2}{*}{ Large stocks } & 0.042 & 40.163 & 35.283 & 29.015 & 21.392 \\
\hline & 1.055 & $(2.174)^{*}$ & $(2.015)^{*}$ & $(3.013)^{*}$ & $(2.036)^{*}$ \\
\hline \multirow[t]{2}{*}{ Largest stocks } & 0.035 & 43.184 & 49.527 & 30.184 & 25.184 \\
\hline & 1.462 & $(2.284)^{*}$ & $(3.014)^{*}$ & $(2.678)^{* *}$ & $(3.155)^{* *}$ \\
\hline \multirow[t]{3}{*}{ All stocks } & 0.041 & 41.264 & 43.327 & 27.183 & 20.174 \\
\hline & 1.553 & $(3.106)^{*}$ & $(3.329)^{*}$ & $(3.522)^{* *}$ & $(3.015)^{* *}$ \\
\hline & $\beta_{1} \sigma_{M}^{2} \times 10^{3}$ & $\beta_{2} \sigma_{L I Q D}^{2} \times 10^{3}$ & $\beta_{3} \sigma_{V o l}^{2} \times 10^{3}$ & $\vartheta\left(\frac{1}{T} \sum_{i=1}^{T} \theta_{i-1}\right)$ & $\times 10^{3}$ \\
\hline \multicolumn{6}{|c|}{ Panel B: Contribution to the momentum returns } \\
\hline \multirow[t]{2}{*}{ Smallest stocks } & 0.038 & 0.025 & 0.042 & 0.021 & \\
\hline & $(2.015)^{*}$ & $(2.103)^{*}$ & $(3.055)^{* *}$ & $(2.013)^{*}$ & \\
\hline \multirow[t]{2}{*}{ Small stocks } & 0.035 & 0.037 & 0.036 & 0.013 & \\
\hline & $(2.154)^{*}$ & $(2.017)^{*}$ & $(2.384)^{* *}$ & 1.553 & \\
\hline \multirow[t]{2}{*}{ Medium stocks } & 0.043 & 0.028 & 0.03 & 0.005 & \\
\hline & $(2.553)^{*}$ & $(2.538)^{*}$ & $(2.053)^{*}$ & 1.038 & \\
\hline \multirow[t]{2}{*}{ Large stocks } & 0.048 & 0.035 & 0.026 & 0.012 & \\
\hline & $(2.083)^{* *}$ & $(2.206)^{*}$ & $(2.562)^{* *}$ & 1.382 & \\
\hline \multirow[t]{2}{*}{ Largest stocks } & 0.046 & 0.031 & 0.021 & 0.016 & \\
\hline & $(2.525)^{* *}$ & $(2.016)^{*}$ & $(2.438)^{*}$ & 1.385 & \\
\hline \multirow[t]{2}{*}{ All stocks } & 0.046 & 0.02 & 0.031 & 0.016 & \\
\hline & $(3.015)^{* *}$ & $(2.173)^{*}$ & $(3.184)^{* *}$ & 1.538 & \\
\hline Proportions & $40.71 \%$ & $17.70 \%$ & $27.43 \%$ & $14.16 \%$ & \\
\hline
\end{tabular}

See above Table 10

SZSE. The results unanimously indicate that, on average, short-to-medium time horizon post-UP-market momentum trading strategies $(\mathrm{R}=3,6,9,12 ; \mathrm{H}=3,6,9,12)$ outperformed post-DOWN-market momentum trading strategies from January 1996 to December 2010. The robustness of the empirical results is confirmed through a risk adjustment procedure based on Wang and Xu's (2004) version of the FF3F model.

The more compelling post-UP-market momentum returns and the depressed postDOWN-market momentum returns can be elucidated under the theoretical framework of heuristics and the bias tradition (Gilovich et al. 2002), aided by three of the most established behavioural theories developed in the momentum effect literature - the 
overconfidence theory (Daniel et al. 1998, 2001), the investors' conservatism model (Barberis et al. 1998) and the investors' under-reaction to the firm-specific news model (Hong and Stein 1999).

Notably, in the SZSE, the magnitude of the asymmetric pattern of market-statedependent momentum returns lags behind that found in the Class A SHSE market for three reasons: (1) a lower occurrence of investors' irrational behaviour, as indicated by lower liquidity and obscure associations between liquidity and cross-sectional stock returns (Baker and Stein 2004); (2) a slightly higher market return volatility (as presented in Table 2) is indicative of a lower contribution towards momentum returns; and (3) the more efficient asset price discovery process created by the direction in which the information travels from domestic investors to institutional investors.

This study differentiates from the most closely related and recent study, that of $\mathrm{He}$ and Chen (2006), ${ }^{35}$ by focusing on the dynamics of momentum investing strategies with short-to-intermediate ranking and holding periods (3-12 months), and applying the market state definitions (12 and 24-month average market returns) which are widely employed in this line of literature for ease of comparison. The empirical evidence found through this research offers a comprehensive view of the asymmetric pattern of the market-state-dependent momentum effect during time periods from January 1996 to December 2010 in the Class A share SHSE and SZSE markets, and reveals evidence of a subdued asymmetric pattern of market-state-dependent momentum returns in the SZSE. Furthermore, we decompose the market-state-dependent momentum returns (Jegadeesh and Titman 1995) and show that the subdued asymmetric pattern in the SZSE is attributable to the low liquidity, higher market return volatility, and weak under-reaction of share prices towards firm-specific information. This evidence further expands the understanding of the dynamics of the market-state-dependent momentum effect.

From a practical standpoint, The Chinese stock market is weakly interrelated to the most developed stock markets (Lin and Swanson 2008) and is deemed as a prime location for global practitioners looking for diversification opportunities amid market swings. A future research avenue could examine the impact of information flows on the asymmetric pattern of the market-state-dependent momentum effect on a global scale by measuring the way that information flows in different markets.

Open Access This article is distributed under the terms of the Creative Commons Attribution 4.0 International License (http://creativecommons.org/licenses/by/4.0/), which permits unrestricted use, distribution, and reproduction in any medium, provided you give appropriate credit to the original author(s) and the source, provide a link to the Creative Commons license, and indicate if changes were made.

\section{Appendices}

See Figs. 1 and 2 and Table 12.

\footnotetext{
35 He and Chen (2006) examined the issue with respect to very short investing time horizons (1-4 weeks) and used a market state definition inconsistent with most of the papers in the literature.
} 
SHSE Share A

\begin{tabular}{c|ccc} 
& UP & DOWN & Total \\
\cline { 2 - 4 } $\mathrm{N}$ & 104 & 76 & 180 \\
$\%$ & $57.78 \%$ & $42.22 \%$ &
\end{tabular}

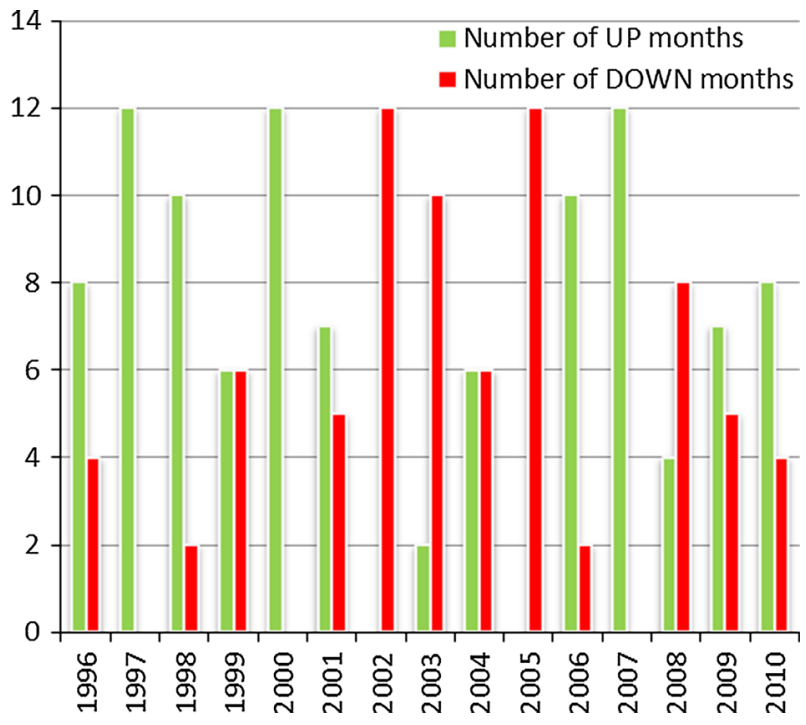

Fig. 1 The number of UP and DOWN market months through the sample period (January 1996-December 2010) for Class A stocks listed in the SHSE (12-month market state). Notes: This figure illustrates the number of UP-market months and DOWN-market months in each calendar year of the sample period (1996-2010). For Class A shares listed in the SHSE, the SSHE (SSE) Share A Index is used to proxy market portfolio. UP market state is defined as when the prior 12-month average market return is positive, while DOWN market state is defined as when the prior 12-months are negative. The number of UP-market months is represented by green columns, and the number of DOWN-market months is represented by red columns 
SZSE share A

\begin{tabular}{c|ccc}
\multicolumn{1}{c}{} & UP & DOWN & Total \\
\cline { 2 - 4 } $\mathrm{N}$ & 101 & 79 & 180 \\
$\%$ & $56.11 \%$ & $43.89 \%$ &
\end{tabular}

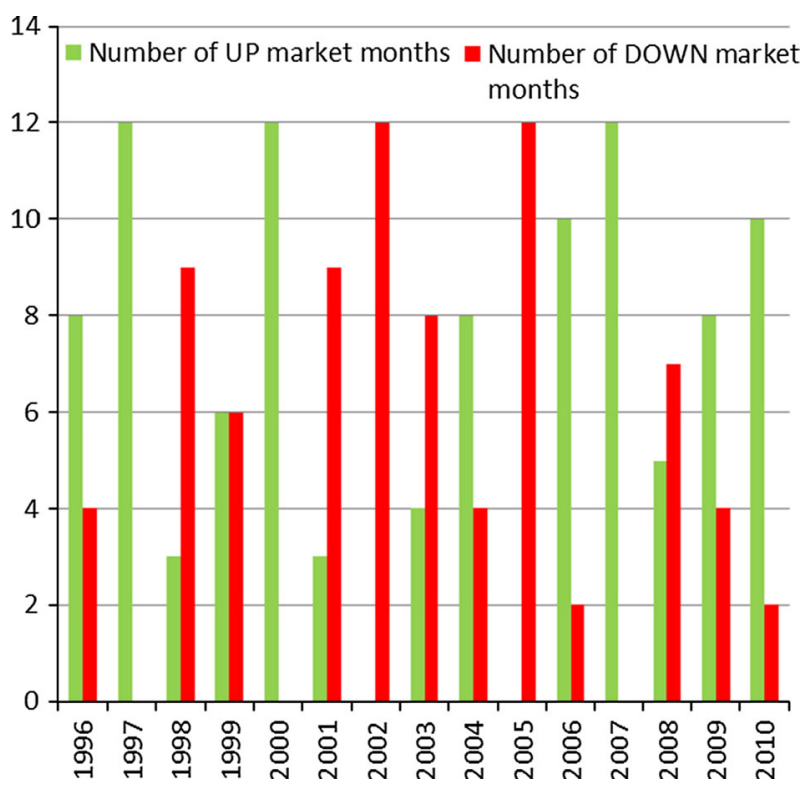

Fig. 2 The number of UP and DOWN market months over the sample period (January 1996-December 2010) for Class A shares listed in the SZSE (12-month market state). Notes: This figure illustrates the number of UP-market months and DOWN-market months in each calendar year of the sample period (1996-2010). For Class A shares listed in the SZSE, SZSE Component A Index is used to proxy market portfolio. UP market state is defined as when the prior 12-month average market return is positive, while DOWN market state is defined as when the prior 12-months are negative. The number of UP-market months is represented by green columns, and the number of DOWN-market months is represented by red columns 
Table 12 Robustness test (adjusting momentum returns using Wang and Xu's (2004) version of the Fama and French three-factor model

\begin{tabular}{llll}
\hline $\mathrm{H}=3$ & $\mathrm{H}=6$ & $\mathrm{H}=9$ & $\mathrm{H}=12$ \\
\hline
\end{tabular}

Risk adjusted based on Wang and Xu (2004)'s version of the FF3F model

a. Risk-adjusted momentum returns for the SHSE of the Chinese Class A share market (UP market12 months)

$\begin{array}{lllll}\mathrm{R}=3 & 0.48^{*} & 0.57^{*} & 0.78^{*} & 0.95 \\ \text { Adjusted } \mathrm{R}^{2} & 0.35 & 0.37 & 0.36 & 0.4 \\ \mathrm{R}=6 & 0.45 & 0.62^{*} & 0.75^{*} & 0.89^{* *} \\ \text { Adjusted } \mathrm{R}^{2} & 0.34 & 0.33 & 0.45 & 0.43 \\ \mathrm{R}=9 & 0.36^{*} & 0.57^{*} & 0.69^{* *} & 0.78^{*} \\ \text { Adjusted } \mathrm{R}^{2} & 0.39 & 0.42 & 0.5 & 0.6 \\ \mathrm{R}=12 & 0.18^{*} & 0.55^{*} & 0.7 * & 0.71^{*} \\ \text { Adjusted } \mathrm{R}^{2} & 0.4 & 0.46 & 0.52 & 0.59\end{array}$

b. Risk-adjusted momentum returns for the SHSE of the Chinese A share market (DOWN market-12 months)

$\mathrm{R}=3$

0.01

0.03

0.05

Adjusted $\mathrm{R}^{2}$

0.32

0.41

0.39

0.4

$\mathrm{R}=6$

$-0.05$

$-0.02 *$

0.01

0.04

Adjusted $\mathrm{R}^{2}$

0.36

0.42

0.48

0.43

$\mathrm{R}=9$

$-0.1$

$-0.05$

$-0.03 *$

0.02

Adjusted $\mathrm{R}^{2}$

0.41

0.47

0.52

0.61

$\mathrm{R}=12$

$-0.15$

$-0.08 *$

$-0.05$

$-0.01$

Adjusted $\mathrm{R}^{2}$

0.41

0.47

0.57

0.63

c. Risk-adjusted momentum returns for the SZSE of the Chinese A share market (UP market-12 months)

\begin{tabular}{lcccc}
$\mathrm{R}=3$ & -0.05 & 0.01 & $0.21^{*}$ & 0.29 \\
Adjusted $\mathrm{R}^{2}$ & 0.42 & 0.48 & 0.51 & 0.49 \\
$\mathrm{R}=6$ & -0.09 & -0.03 & 0.14 & 0.19 \\
Adjusted $\mathrm{R}^{2}$ & 0.53 & 0.49 & 0.58 & 0.53 \\
$\mathrm{R}=9$ & -0.12 & $-0.02^{*}$ & $0.15^{*}$ & 0.25 \\
Adjusted $\mathrm{R}^{2}$ & 0.58 & 0.49 & 0.57 & 0.61 \\
$\mathrm{R}=12$ & -0.1 & $-0.05^{*}$ & $0.07^{*}$ & 0.16 \\
Adjusted $\mathrm{R}^{2}$ & 0.55 & 0.62 & 0.55 & 0.6 \\
\hline
\end{tabular}


Table 12 continued

\begin{tabular}{|c|c|c|c|c|}
\hline & $\mathrm{H}=3$ & $\mathrm{H}=6$ & $\mathrm{H}=9$ & $\mathrm{H}=12$ \\
\hline \multicolumn{5}{|c|}{$\begin{array}{l}\text { d. Risk-adjusted momentum returns for the SZSE of the Chinese A share market (DOWN market-12 } \\
\text { months) }\end{array}$} \\
\hline $\mathrm{R}=3$ & -1.19 & -1.08 & -0.95 & -0.83 \\
\hline Adjusted $\mathrm{R}^{2}$ & 0.42 & 0.47 & 0.42 & 0.49 \\
\hline $\mathrm{R}=6$ & -1.23 & -1.15 & -1.06 & -0.95 \\
\hline Adjusted $\mathrm{R}^{2}$ & 0.39 & 0.54 & 0.52 & 0.6 \\
\hline $\mathrm{R}=9$ & -1.26 & -1.18 & -1.09 & -0.97 \\
\hline Adjusted $\mathrm{R}^{2}$ & 0.48 & 0.52 & 0.43 & 0.5 \\
\hline $\mathrm{R}=12$ & -1.31 & -1.22 & -1.04 & -1.02 \\
\hline Adjusted $\mathrm{R}^{2}$ & 0.42 & 0.51 & 0.47 & 0.48 \\
\hline
\end{tabular}

a. This table reports the risk-adjusted momentum returns of sixteen different momentum trading strategies with different combinations of ranking periods $(R=3,6,9,12)$ and holding periods $(H=3,6,9,12)$ in the Chinese Class A share market (SHSE/SZSE) for the entire sample period from January 1996 to December 2010 over the time periods following the UP (DOWN) market state (defined by a positive (negative) prior 12month market average return). In light of the structure of Wang and Xu (2004)'s version of the FF3F model, the risk-adjusted momentum returns are calculated by regressing the corresponding raw momentum of different momentum trading strategies against three risk factors, namely the market risk factor $\left(R_{m, t}-R_{f, t}\right)$, firm size effect factor $\left(S M B_{t}\right)$, and residual free-float ratio factor $\left(R F F_{-} H M L_{t}\right)$. Mathematically, it can be expressed as $R_{(W-L), t}-R_{f, t}=\alpha+\beta\left(R_{m, t}-R_{f, t}\right)+s\left(S M B_{t}\right)+f\left(R F F_{-} H M L_{t}\right)+e_{t} . R_{(W-L), t}$ is the momentum returns calculated by taking the difference between the average monthly returns of "winner" portfolios and those of "loser" portfolios; $R_{f, t}$ is the risk-free rate, proxied by the monthly yield of the China three-month lump-sum deposit rate; $R_{m, t}$ denotes the average monthly return of the market portfolio, estimated by the average monthly return of value-weighted Class A shares Index, including all of the eligible Class A shares listed in the SHSE/SZSE; $S M B_{t}$ is the difference between the average monthly returns of portfolios consisting of $20 \%$ of all the eligible Class A shares with the smallest capitalization and those of portfolios comprising $20 \%$ of all eligible Class A shares with the biggest capitalization ranked in June of each year, also known as the size effect (firm size) factor; $R F F \_H M L_{t}$ represents the difference between the average monthly returns of portfolios consisting of $20 \%$ of all eligible Class A shares with the highest residual free-float ratios - resulted from regressing free-float ratios against log market capitalizations of corresponding firms - and those of portfolios with $20 \%$ of all eligible Class A shares with the lowest free-float ratios, known as the strength of corporate governance factor at different time points. $\alpha$ represents the portion of the raw momentum return that cannot be justified by the three aforementioned risk factors embedded in Wang and Xu's (2004) version of the FF3F model. $\beta, s, f$ are the factor loadings (coefficients) from the regressing estimation procedure on the market risk factor $\left(R_{m, t}-R_{f, t}\right)$, size effect factor $\left(S M B_{t}\right)$, and the strength of corporate governance $\left(R F F \_H M L_{t}\right)$ respectively, specifying the explanatory power of each risk factor over the raw momentum returns. $e_{t}$ is an error factor, which is independently and identically distributed. The adjusted $\mathrm{R}^{2}$ is specified for the risk-adjusted momentum return of each momentum trading strategy, indicating that the percentage of variation in raw momentum returns can be jointly explained by the three risk factors, taking into account the number of regressors (risk factors). The number of asterisks indicates the statistical significance of the risk-adjusted momentum returns, with one asterisk showing that the relevant risk-adjusted momentum return is statistically significant at the $10 \%$ level while two show that the relevant risk-adjusted momentum return is statistically significant at the $5 \%$ level. All the risk-adjusted momentum returns are presented in percentages

b. Note: See note below Table a

c. Note: see note below table a

d. Note: see note below table a 


\section{References}

Ang, A., Hodrick, R. J., Xing, Y., \& Zhang, X. (2006). The cross-section of volatility and expected returns. The Journal of Finance, 61(1), 259-299.

Antoniou, C., Doukas, J. A., \& Subrahmanyam, A. (2013). Cognitive dissonance, sentiment, and momentum. Journal of Financial and Quantitative Analysis, 48(1), 245-275.

Antoniou, A., Galariotis, E. C., \& Spyrou, S. I. (2006). Short-term contrarian strategies in the London stock exchange: Are they profitable? which factors affect them? Journal of Business Finance and Accounting, 33(5-6), 839-867.

Arena, M. P., Haggard, K. S., \& Yan, X. (2008). Price momentum and idiosyncratic volatility. Financial Review, 43(2), 159-190.

Baker, M., \& Stein, J. C. (2004). Market liquidity as a sentiment indicator. Journal of Financial Markets, 7(3), 271-299.

Barberis, N., Shleifer, A., \& Vishny, R. (1998). A model of investor sentiment. Journal of Financial Economics, 49(3), 307-343.

Benartzi, S., \& Thaler, R. H. (2001). Naive diversification strategies in defined contribution saving plans. The American Economic Review, 91(1), 79-98.

Bless, H., \& Schwarz, N. (1999). Sufficient and necessary conditions in dual-process models-The case of mood and information processing. In S. Chaiken \& Y. Trope (Eds.), Dual process theories in social psychology (pp. 423-440). New York: The Guilford.

Chan, K., Menkveld, A. J., \& Yang, Z. (2007). The informativeness of domestic and foreign investors' stock trades: Evidence from the perfectly segmented Chinese market. Journal of Financial Markets, 10(4), $391-415$.

Chordia, T., \& Shivakumar, L. (2002). Momentum, business cycle, and time-varying expected returns. The Journal of Finance, 57(2), 985-1019.

Chui, A., \& Kwok, C. (1998). Cross-autocorrelation between A shares and B shares in the Chinese stock market. Journal of Financial Research, 21(3), 333-353.

Claessens, S. (1997). Corporate governance and equity prices: Evidence from the Czech and Slovak Republics. The Journal of Finance, 52(4), 1641-1658.

Cooper, M., Gutierrez, R., \& Hameed, A. (2004). Market states and momentum. The Journal of Finance, 59(3), 1345-1365.

Daniel, K., Hirshleifer, D., \& Subrahmanyam, A. (1998). Investor psychology and security market underand overreactions. The Journal of Finance, 53(6), 1839-1885.

Daniel, K., Hirshleifer, D., \& Subrahmanyam, A. (2001). Overconfidence, arbitrage, and equilibrium asset pricing. The Journal of Finance, 56(3), 921-965.

Du, D., Huang, Z., \& Liao, B. (2009). Why is there no momentum in the Taiwan stock market? Journal of Economics and Business, 61(2), 140-152.

Du, J. (2002). Heterogeneity in Investor Confidence and Asset Market Under-and Overreaction. Resource document. http://papers.ssrn.com/sol3/papers.cfm?abstract_id=302684. Accessed 7 Sept 2015.

Galariotis, E. C., Holmes, P., \& Ma, X. S. (2007). Contrarian and momentum profitability revisited: Evidence from the London Stock Exchange 1964-2005. Journal of Multinational Financial Management, 17(5), $432-447$.

Gilovich, T., Griffin, D. W., \& Kahneman, D. (2002). Heuristics and biases: The psychology of intuitive judgement. Cambridge: Cambridge University Press.

Griffin, D., \& Tversky, A. (1992). The weighing of evidence and the determinants of confidence. In T. Gilovich, D. W. Griffin, \& D. Kahneman (Eds.), Heuristics and Biases: The Psychology of Intuitive Judgment (pp. 230-249). Cambridge: Cambridge University Press.

Hanauer, M. (2014). Is Japan different? evidence on momentum and market dynamics. International Review of Finance, 14(1), 141-160.

Harvey, C. R., \& Siddique, A. (2000). Conditional skewness in asset pricing tests. The Journal of Finance, 55(3), 1263-1295.

He, X.-H., \& Chen, Z. (2006). An empirical research on stock markets: Momentum effect in bull and bear markets. The Theory and Practice of Finance and Economics, 27, 40-44.

He, Y., \& Tan, J. (2006). Momentum, Reversal and Overreaction: Empirical Results from Chinese Stock Market. The Sixth Wuhan International Conference on E-Business. 1809-1814.

Hon, M., \& Tonks, I. (2003). Momentum in the UK stock market. Journal of Multinational Financial Management, 13(1), 43-70. 
Hong, H., \& Stein, J. (1999). A Unified theory of under-reaction, momentum trading, and overreaction in asset markets. The Journal of Finance, 54(6), 2143-2184.

Huang, D. (2006). Market states and international momentum strategies. Quarterly Review of Economics and Finance, 46(3), 437-446.

Jegadeesh, N., \& Titman, S. (1993). Returns to buying winners and selling losers: Implications for stock market efficiency. The Journal of Finance, 48(1), 65-91.

Jegadeesh, N., \& Titman, S. (1995). Overreaction, delayed reaction, and contrarian profits. The Review of Financial Studies, 8(4), 973-993.

Jiang, G., Li, D., \& Li, G. (2011). Capital investment and momentum strategies. Review of Quantitative Finance and Accounting, 39(2), 1-24.

Johnson, T. (2002). Rational momentum effects. The Journal of Finance, 57(2), 585-608.

Kahneman, D., \& Frederick, S. (2002). Representativeness revisited: Attribute substitution in intuitive judgment. In T. Gilovich, D. Griffin, \& D. Kahneman (Eds.), Heuristics and biases: The psychology of intuitive judgment (pp. 49-81). Cambridge: Cambridge University Press.

Lehmann, B. (1990). Fads, martingales, and market efficiency. The Quarterly Journal of Economics, 105(1), $1-28$.

Lin, A., \& Swanson, P. (2008). The effect of China's reform policies on stock market information transmission. Quarterly Journal of Finance and Accounting, 47(3), 49-76.

Moskowitz, T. J., \& Grinblatt, M. (1999). Do industries explain momentum? The Journal of Finance, 54(4), 1249-1290.

Nayayan, P. K., \& Zheng, X. (2010). Market liquidity risk factor and financial market anomalies: Evidence from the Chinese stock market. Pacific-Basin Finance Journal, 18(5), 509-520.

Naughton, T., Truong, C., \& Veeraraghavan, M. (2008). Momentum strategies and stock returns: Chinese evidence. Pacific-Basin Finance Journal, 16(4), 476-492.

Newey, W. K., \& West, K. D. (1987). A simple positive definite heteroskedasticity and autocorrelation consistent covariance matrix. Econometrica, 55, 703-708.

Pastor, L., \& Stambaugh, R. F. (2003). Liquidity risk and expected stock returns. Journal of Political Economy, 111(3), 642-685.

Phua, V., Chan, H., Faff, R., \& Hudson, R. (2010). The influence of time, seasonality and market state on momentum: insights from the Australian stock market. Applied Financial Economics, 20(19-21), 1547-1563.

Phylaktis, K., \& Ravazzolo, F. (2005). Stock market linkages in emerging markets: Implications for international portfolio diversification. Journal of International Financial Markets, Institutions and Money, 15(2), 91-106.

Sagi, J., \& Seasholes, M. (2007). Firm-specific attributes and the cross-section of momentum. Journal of Financial Economics, 84(2), 389-434.

Schwarz, N. (1990). Feelings as information: Informational and motivational functions of affective states. New York: Guilford Press.

Seiler, M. J., Harrison, D. M., Van Vliet, P., \& Yeung, K. C. (2005). Return characteristics of state-owned and non-state-owned Chinese A shares. The Financial Review, 40(4), 533-548.

Sharpe, W. F. (1964). Capital asset prices: A theory of market equilibrium under conditions of risk. The Journal of Finance, 19(3), 425-442.

Shefrin, H. (2000). Beyond greed and fear: Understanding behavioral finance and the psychology of investing. New York: Oxford University Press.

Siganos, A., \& Chelley-Steeley, P. (2006). Momentum profits following bull and bear markets. Journal of Asset Management, 6(5), 381-388.

Sjöö, B., \& Zhang, J. (2000). Market segmentation and information diffusion in China's stock markets. Journal of Multinational Financial Management, 10(3-4), 421-438.

Stivers, C. T., \& Sun, L. (2009). Cross-sectional return dispersion and time-variation in value and momentum premiums. Journal of Financial and Quantitative Analysis, 45(4), 987-1014.

Su, Q., \& Chong, T. T.-L. (2007). Determining the contributions to price discovery for Chinese cross-listed stocks. Pacific-Basin Finance Journal, 15(2), 140-153.

Tiedens, L. Z., \& Linton, S. (2001). Judgment under emotional certainty and uncertainty: The effects of specific emotions on information processing. Journal of Personality and Social Psychology, 81(6), 973-988. 
Treynor, J. L. (1962). Toward a Theory of Market Value of Risky Assets. Unpublished manuscript. "Rough Draft" dated by Mr. Treynor to the fall of 1962. A final version was published in 1999, in Asset Pricing and Portfolio Performance (pp. 15-22). London: Robert A. Korajczyk (editor). Risk Books.

Wang, C., \& Chin, S. (2004). Profitability of return and volume-based investment strategies in China's stock market. Pacific-Basin Finance Journal, 12(5), 541-564.

Wang, F., \& Xu, Y. (2004). What determines Chinese stock returns? Financial Analysts Journal, 60(6), $65-77$.

Wang, K. Q., \& Xu, J. (2015). Market volatility and momentum. Journal of Empirical Finance, 30(1), 79-91.

Wang, K.-Y., Jiang, C.-H., \& Huang, Y.-S. (2009). Market States and the profitablity of momentum strategies: Evidence from the Taiwan stock exchange. The International Journal of Business and Finance Research, 3(1), 89-102.

Wang, P., Liu, A., \& Wang, P. (2004). Return and risk interactions in Chinese stock markets. Journal of International Financial Markets Institutions and Money, 14(4), 367-383.

$\mathrm{Wu}$, Y. (2011). Momentum trading, mean reversal and overreaction in Chinese stock market. Review of Quantitative Finance and Accounting, 37(3), 301-323.

Wu, Y., \& Choudhry, T. (2015). Momentum phenomenon in the Chinese Class A and B share markets. Review of Behavioural Finance, 7(2), 116-133.

$\mathrm{Xu}, \mathrm{X} .$, \& Wang, Y. (1999). Ownership structure and corporate governance in Chinese stock companies. China Economic Review, 10(1), 75-98.

Yang, J. (2003). Market segmentation and information asymmetry in Chinese stock markets: A VAR analysis. The Financial Review, 38(4), 591-609.

Yates, J. F., Lee, J. W., Shinotsuka, H., Patalano, A. L., \& Sieck, W. (1998). Cross-cultural variations in probability judgment accuracy: Beyond general knowledge overconfidence? Organizational Behaviour and Human Decision Processes, 74(2), 89-117. 